Journal of Environmental
AnSN: $2525-815 \mathrm{X}$

\title{
Variação temporal e espacial da artropodofauna associada a Ipomoea carnea subs. fistulosa (Convolvulaceae) em um ecossistema de Floresta Tropical Seca
}

\section{Temporal and spatial variation of the arthropodofauna associated with Ipomoea carnea subs. fistulosa (Convolvulaceae) in an ecosystem of Tropical Rainforest}

\author{
Joanny Kelly Silva dos Santos Martins ${ }^{\mathrm{a}}$, Luciana Soares de Souza ${ }^{\mathrm{b}}$, Andreia Garcia Carneiro ${ }^{\mathrm{b}}$, \\ Jarcilene Silva de Almeida-Cortez ${ }^{\mathrm{c}}$

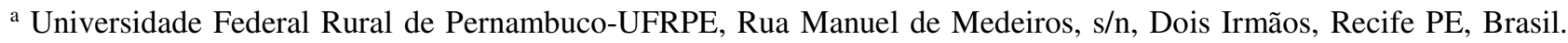 \\ CEP: 52171-900. E-mail: joanny.bio@ gmail.com. \\ b Universidade Federal de Campina Grande-UFCG, Avenida Universitária, s/n, Jatobá, Patos-PB, Brasil. CEP: 58708- \\ 110. E-mail: luciana-vaz@ hotmail.com, andreia9916.ag@gmail.com. \\ ${ }^{c}$ Universidade Federal de Pernambuco-UFPE, Avenida Prof. Moraes Rego, n. 1235, Cidade Universitária, Recife-PE, \\ Brasil. E-mail: 50670-9010. E-mail: cortez_jarcy@yahoo.com.
}

\begin{tabular}{l}
\hline A R T I C L E I N F O \\
\hline Recebido 07 Jul 2018 \\
Aceito 04 Set 2018 \\
Publicado 24 Set 2018
\end{tabular}

\begin{abstract}
A B S T R A C T
Plants as producers, represent the energy source for the entire network of consumers and their reproductive success interfere directly and indirectly in the structure of food webs (bottom-up effect). The interactions between plants and animals, both for pollination and for protection against herbivores, are fundamental for the maintenance of communities. The study aimed to evaluate the spatial and temporal variations that occur in the multitrophic interactions in a model plant of two Caatinga areas. It was made inventories of arthropods associated with Ipomoea carnea subs. fistulosa over eight months in a more preserved Caatinga area, surrounded by a natural reserve, in a farm with biodynamic maintenance in Santa Terezinha (area 1). Another area, anthropized urban ecosystem in the city of Patos (area 2), both in Paraiba. The preserved area presented greater abundance and richness for each trophic level. While in the urban ecosystem there was a significant reduction of arthropod richness and abundance, with different species occurring in both areas, with greater richness and complexity of interactions in the preserved area, occurring herbivores, predators and parasitoids, there was no record of parasitoids in the urban area. Therefore, in urban environments, a reduction in density and richness in species can occur, as well as a change in the structure and dynamics of the plant communities and the interactions around them, which justifies the pattern of abundance and species richness. Thus, the high rate of destruction of dry tropical forests requires the development of strategies for the conservation and sustainable use of the remaining fragments.
\end{abstract}

Keywords: Multitrophic interactions, pollinators, herbivores, predators, parasitoids, caatinga. 
Caatinga mais preservada, rodeada por uma reserva natural em Santa Terezinha, Paraíba (área preservada). Foi investigada uma outra área antropizada, de ecossistema urbano, na cidade de Patos, Paraíba (área urbana). A área preservada apresentou maior abundância e riqueza para cada nível trófico, enquanto na área urbana houve uma significativa redução de riqueza e abundância de artrópodes, ocorrendo diferentes espécies em ambas as áreas, com maior riqueza e complexidade de interações na área preservada. Enquanto na área preservada houveram herbívoros, predadores e parasitoides, na área urbana houveram apenas herbívoros e predadores, representados por poucas espécies. Podemos afirmar que, em ambientes fragmentados sob intensa ação antrópica, pode ocorrer uma redução na densidade e riqueza em espécies, assim como uma alteração na estrutura e dinâmica das comunidades de plantas e as interações acerca delas, o que justifica o padrão de abundância e riqueza de espécies registrado. A alta velocidade de destruição de florestas tropicais secas exige o desenvolvimento de estratégias de conservação e uso sustentável dos fragmentos remanescentes.

Palavras-Chave: Interações multitróficas, polinizadores, herbívoros, predadores, parasitóides, caatinga.

\section{Introdução}

As interações multitróficas constituem sistemas onde várias espécies interagem simultaneamente e a evolução dessas interações resulta do desenvolvimento de adaptações cada vez mais sofisticadas, capazes de promover associações como uma forma de sobrevivência dos organismos interagentes (Thompson, 1999). As plantas como produtores representam a fonte de energia para toda a rede de consumidores e o seu sucesso reprodutivo interfere direta e indiretamente na estruturação das cadeias tróficas (efeito bottomup) (Rzanny et al., 2013; Folkard \& Smith, 1995). Com isso, as interações entre plantas e animais, tanto para polinização (Kill, 2018) quanto para proteção contra herbívoros (Corrêa et al., 2008; Oliveira \& Freitas, 2004; Del Claro, 2004) são fundamentais para a manutenção das comunidades.

A maioria das teias alimentares é formada por pelo menos três níveis tróficos: produtores, herbívoros e os inimigos naturais dos herbívoros. Como os insetos herbívoros constituem alimento para predadores e parasitoides, a abundância de herbívoros e a disponibilidade de recursos vegetais podem afetar o próximo nível trófico (Alencar et al., 2018; Price et al., 1980). As condições ambientais podem intensificar $o$ ataque por herbívoros, como por exemplo, em solos secos com baixa quantidade de nutrientes disponíveis (Gullan \& Cranston, 2007; Crawley, 1983; Edwards \& Wratten, 1981). Plantas que sofrem estresse hídrico ou nutricional, em geral, constituem melhor fonte de alimento do que aquelas não-estressadas, por possuírem maior disponibilidade de nitrogênio solúvel e menor concentração de compostos de defesa (Oliveira et al., 2014; White, 1984).

A degradação dos ecossistemas tem ocorrido num ritmo acelerado, isso tem levado o ambiente a perder sua identidade, proporcionando uma diminuição na heterogeneidade biológica, com isso, há a necessidade de se conhecer essa diversidade e desenvolver estratégias mais racionais para o uso dos recursos naturais (Santos et al., 2011). O registro da diversidade biológica deve ser feito inicialmente, pelo levantamento das espécies que ocorrem em cada região, incluindo aspectos como variação espacial entre os ambientes e variação temporal. A caatinga assim como as outras vegetações, vem passando por um intenso processo de devastação ambiental, provocado pelo uso insustentável dos seus recursos naturais (Albuquerque et al., 2012; Santos et al., 2011), por isso, a realização de estudos em áreas com características da cobertura original são de grande importância para subsidiar programas de manejo e conservação. Os insetos são considerados bons indicadores para avaliar as condições ambientais, devido a sua grande diversidade de espécies e hábitos, compreendendo aproximadamente $70 \%$ das espécies animais conhecidos (Gullan \& Cranston, 2008). Além de desempenharem papéis importantes em vários processos biológicos nos ecossistemas naturais, os insetos respondem rapidamente às mudanças súbitas no ambiente $\mathrm{e}$ podem oferecer excelentes informações para a interpretação de tais mudanças (Hutcheson, 1990). $\mathrm{O}$ estudo objetivou avaliar as variações espaciais e temporais que ocorrem nas interações multitróficas em plantas conspícuas em duas áreas de Caatinga. Para tanto, utilizamos como modelo ecológico a espécie Ipomoea carnea subs. fistulosa, visando testar as seguintes hipóteses: 1) A artropodofauna associada a espécie terá maior riqueza de espécies e maior abundância de indivíduos em área preservada do que em área urbanizada 2) Haverá uma maior complexidade de níveis tróficos, em áreas preservadas do que em áreas urbanizadas.

\section{Material e Métodos}

Área de estudo

$\mathrm{O}$ estudo foi realizado em duas áreas distantes entre si cerca de $18 \mathrm{~km}$ na BR 361, ambas 
estão inseridas no semiárido nordestino, portanto, marcada pelas secas, bem como pelas chuvas inconstantes distribuídas irregularmente ao longo de todo ano. O período de amostragem se estendeu de agosto de 2014 a março de 2015. Nas áreas estudadas, os maiores índices de precipitação pluviométrica ocorrem entre janeiro e abril e o restante do ano consiste em estiagem, tendo como média anual das precipitações pluviométricas 600 $\mathrm{mm}$. A estação seca inicia-se, geralmente, em maio e prolonga-se até janeiro. Tem como predominância a formação da Caatinga, com clima quente e seco (Ico et al., 2014). Apesar de as populações de plantas modelo não se encontrarem dentro da área de reserva, existia na área experimental manchas de vegetação de Caatinga típica, estando localizada a cerca de $2 \mathrm{~km}$ da área de mata preservada.

\section{Área preservada}

A área preservada em estudo localiza-se na Fazenda Tamanduá, no Município de Santa Terezinha (7 ${ }^{\circ}$ '20' latitude Sul e $37^{\circ} 26^{\prime} 43^{\prime \prime}$ ' longitude Oeste), propriedade da Mocó Agropecuária Ltda., no município de Santa Terezinha, Paraíba, distante $20 \mathrm{~km}$ da cidade de Patos. Trata-se de uma área de, aproximadamente, 3000 ha, onde 900 ha são destinados à Reserva Particular do Patrimônio Natural, RPPN Tamanduá, área de preservação reconhecida pelo IBAMA-PB através de Portaria $\mathrm{N}^{\circ} 110 / 98-\mathrm{N}$ e vários fragmentos em diferentes estádios de sucessão (Cabral et al., 2013; Silva et al., 2012). A área da reserva legal, ocupa 325 ha e por cerca de trinta anos não sofre ação antrópica. A fazenda apresenta sistemas sustentáveis de agricultura que não permitem o uso de produtos químicos sintéticos prejudiciais para a saúde humana e para o meio ambiente.

\section{Área urbana}

Trata-se de uma área antropizada, localizada às margens da PB-110, saída para Teixeira, próxima ao Campus da Universidade Federal de Campina Grande (37 $11^{\prime} 26^{\prime \prime}$ a $37^{\circ} 18^{\prime} 38^{\prime \prime}$ de longitude a oeste de Greenwich e $7^{\circ} 03^{\prime} 32^{\prime \prime}$ ' a 7 $7^{\circ} 13$ '32" de latitude sul), no município de Patos (Paraíba), Nordeste do Brasil. A vegetação original da área onde o estudo foi conduzido é tipicamente de Caatinga, atualmente apresentando ação antrópica e incremento de plantas introduzidas.

\section{Sistema de estudo}

Ipomoea carnea subsp. fistulosa (Mart. ex Choisy) D.F. Austin é uma planta nativa do Brasil (Simão-Bianchini \& Ferreira, 2015), perene e resistente a longos períodos de seca, sendo amplamente distribuída no país, com predominância em ambientes de áreas abertas, antropizadas e campos de várzea (Simão-Bianchini $\&$ Ferreira, 2014). Sendo uma planta que apresenta flores conspícuas e muitos nectários extraflorais, é uma espécie bastante atrativa a insetos. Apresenta antese diurna (Maimoni-Rodella \& Yanagizawa, 2007) e é polinizada por uma variedade de abelhas, tais como, Ancylocelis, Ceratina, Melitoma, Ptilothrix, Trigona e Apis, entre outras (Kiill \& Ranga, 2003; Schlising, 1970). Atrai várias espécies de formigas e outros artrópodes predadores devido à presença de NEFs-Nectários Extraflorais, sendo dois localizados na face abaxial das folhas, e cinco na base das sépalas de flores e nos botões (Paz et al., 2016), que, de acordo com Frey (1995), têm função defensiva contra herbivoria, mas, apesar disso, Keeler (1975) registrou uma alta taxa de herbivoria. Além disso, esta espécie é uma das poucas que persistem floridas e com folhas no período de estiagem nas áreas de estudos.

\section{Coleta da artropodofauna}

Polinizadores, herbívoros (florívoros e folívoros), predadores de frutos e predadores de outros insetos foram coletados durante oito meses (agosto de 2014 a março de 2015) nas duas unidades amostrais para registro da riqueza e abundância, com coletas realizadas, mensalmente, em dois dias consecutivos, das 5 h00min às 14h00min, com intervalos de 10 minutos, em cada uma das áreas. Os espécimes foram coletados, manualmente, e com uso de redes entomológicas, onde posteriormente os hexápodes foram montados em alfinetes entomológicos e devidamente etiquetados. Os aracnídeos foram armazenados em meio líquido (álcool a 70\%). Coleoptera, Diptera e Hemiptera foram identificados com uso de chaves de identificação. Os Hymenoptera (Formicidae e não-Formicidae) e Araneae foram identificados por especialistas. $\mathrm{O}$ recurso coletado pelos herbívoros foi registrado no momento da coleta, e os mesmos foram classificados quanto a guilda em mastigadores e sugadores pelo aparelho bucal. Os visitantes florais foram classificados como polinizadores quando contatavam anteras e estigma e como pilhadores quando coletava os recursos florais sem contatar os órgãos reprodutivos durante a visita ou quando "roubavam" os recursos florais por vias ilegítimas.

\section{Análise da artropodofauna}

Os artrópodes foram caracterizados de acordo com o número de espécies, gêneros e famílias dos espécimes coletados. A frequência das 
espécies foi calculada através da fórmula $\mathrm{F}=\mathrm{n}^{\circ}$ de meses em que a espécie $\mathrm{X}$ foi coletada / $\mathrm{n}^{\mathrm{o}}$ total de meses de coleta $\mathrm{x} 100$, e classificadas conforme Silveira Neto (1976) em constante > 50\%, acessória $>25-50 \%$ e acidental $<25 \%$. A dominância das espécies foi definida de acordo com as categorias estabelecidas de Friebe (1983), sendo eudominante $>10 \%$, dominante $>5-10 \%$, subdominante $>2-5 \%$, recessiva $=1-2 \%$ e rara $<$ $1 \% . \mathrm{D} \%=(\mathrm{i} / \mathrm{t}) \cdot 100$, onde i é o total de indivíduos de uma espécie e t o total de indivíduos coletados. Foram realizados o índice de Riqueza Jackknife $1^{a}$ Ordem e Índice de diversidade de Margalef, através do pacote DivEs - Diversidade de Espécies 4.1 .

\section{Análise estatística}

Foi realizado um teste $t$ de Student para análise de possíveis diferenças na abundância dos indivíduos por grupos tróficos. Para avaliar as relações entre as abundâncias de cada nível trófico entre si e com a precipitação pluviométrica foi utilizado o teste de regressão linear simples e múltipla. As análises estatísticas foram testadas a $5 \%$ de significância, através do software Biostat 5.3 .

\section{Resultados}

Foi coletado um total de 7.199 indivíduos (Área preservada $=5848$; Área urbana $=1351$ ), pertencentes a cinco grupos presentes em ambas as áreas estudadas, sendo um grupo da ordem Araneae e quatro grupos de hexápodes pertencentes às seguintes ordens: Coleoptera, Hymenoptera, Diptera e Hemiptera. Para a Área preservada, foi registrado um total 158 espécies de insetos e 11 espécies de aranhas, totalizando 169 espécies (Tabela 1). Para a área urbana foi registrado um total de 66 espécies, dos quais 3 são espécies de aranhas e os demais são insetos (Tabela 2).

Tabela 1. Número de espécies e indivíduos de artrópodes por táxon associados a Ipomoea carnea subs. fistulosa amostrados na área de Caatinga preservada, em Santa Terezinha, Paraíba, Brasil.

\begin{tabular}{ccccc}
\hline Ordem & $\mathbf{R}$ & $\mathbf{R}(\boldsymbol{\%})$ & $\mathbf{N}$ & $\mathbf{N}(\boldsymbol{\%})$ \\
\hline Coleoptera & 65 & 38,46 & 4287 & 73,30 \\
Hymenoptera & 52 & 30,76 & 1274 & 21,78 \\
Diptera & 26 & 15,38 & 92 & 1,57 \\
Hemiptera & 15 & 8,87 & 46 & 0,78 \\
Araneae & 11 & 5,50 & 62 & 1,06 \\
\hline Total & 169 & 100 & 5848 & 100 \\
\hline
\end{tabular}

Tabela 2. Número de espécies e indivíduos de artrópodes por táxon associados a Ipomoea carnea subs. fistulosa amostrados na área de Caatinga urbana, em Patos, Paraíba, Brasil.

\begin{tabular}{ccccc}
\hline Ordem & $\mathbf{R}$ & $\mathbf{R}(\boldsymbol{\%})$ & $\mathbf{N}$ & $\mathbf{N}(\boldsymbol{\%})$ \\
\hline Coleoptera & 16 & 24,24 & 781 & 57,80 \\
Hymenoptera & 27 & 40,90 & 495 & 36,63 \\
Diptera & 15 & 22,72 & 50 & 3,70 \\
Hemiptera & 5 & 7,57 & 10 & 0,74 \\
Araneae & 3 & 4,54 & 15 & 1,11 \\
\hline Total & 66 & 100 & 1351 & 100 \\
\hline
\end{tabular}

A abundância das espécies em geral foi significativamente maior na Área preservada (Teste T de Student: GL $=184,4 ; p=0,03$ ). As ordens Coleoptera, Hymenoptera, Hemiptera, e Araneae apresentaram maior abundância na área preservada, porém para a ordem Diptera a diferença na abundância não foi significativa (Figura 1).
A diversidade e riqueza de espécies foi maior na área preservada, onde a riqueza de espécies estimada pelo índice de riqueza de Jackknife foi a riqueza observada. O contrário ocorreu para a área urbana, a qual mostrou uma riqueza de espécies inferior à riqueza estimada por este índice (Tabela $3)$. 

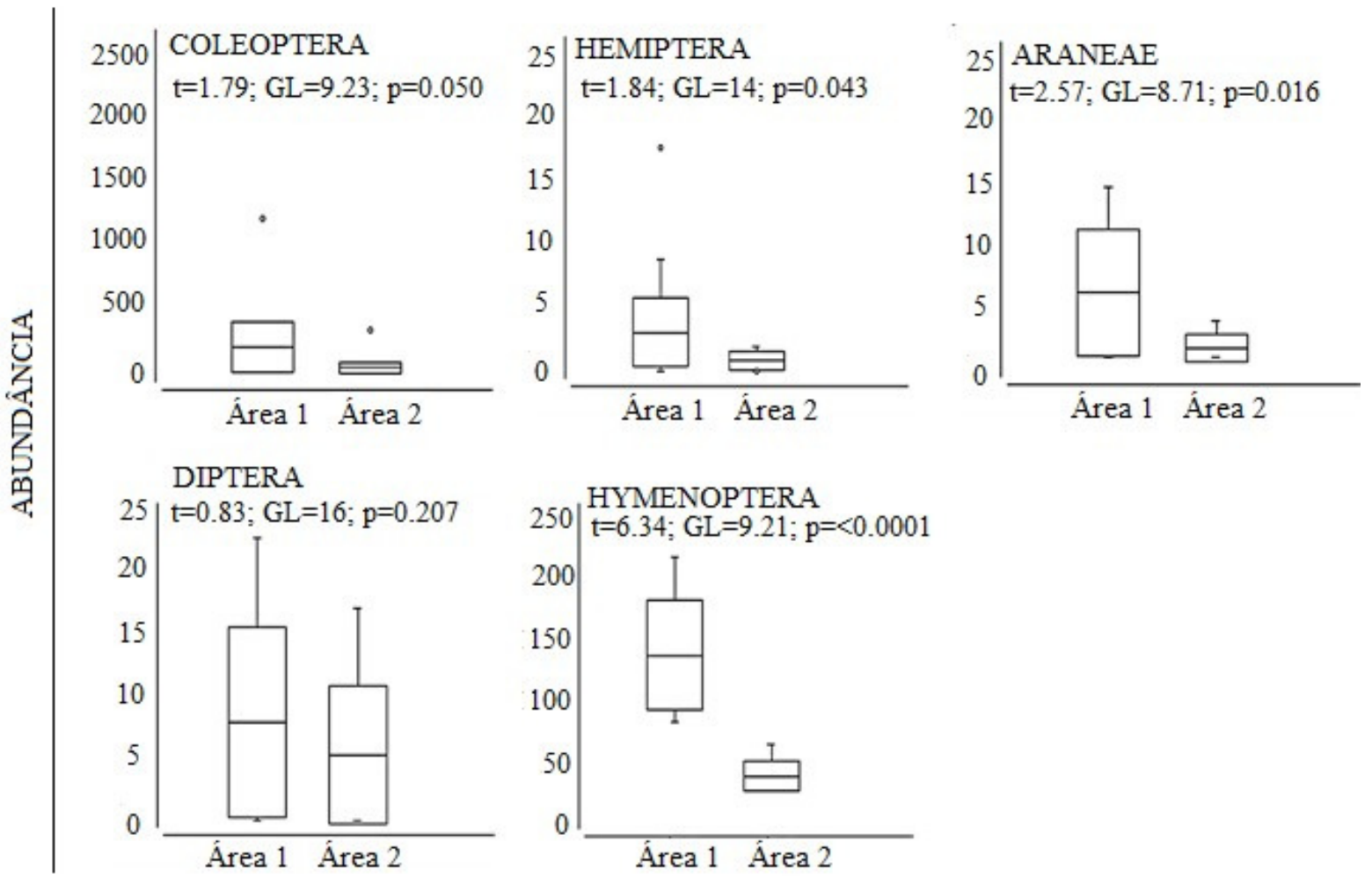

Figura 1. Teste t de Student da abundância de indivíduos por ordens de artrópodes associados em Ipomoea carnea subs. fistulosa entre a preservada e a área urbana.

Tabela 3. Abundância, riqueza e diversidade de artrópodes associados em Ipomoea carnea subs. fistulosa em duas áreas: área preservada e a área urbana.

\begin{tabular}{lcccc}
\hline Áreas & $\mathbf{N}$ & $\ldots \ldots$ Riqueza Jackknife $\mathbf{1}^{\mathbf{a}}$ Ordem & \multirow{2}{*}{ Diversidade de Margalef } \\
\hline Urbana & 5.848 & 169 & SÖbs & \\
Preservada & 1.351 & 99 & 169 & 44,67 \\
\hline
\end{tabular}

\section{Estrutura trófica e sazonalidade}

Os artrópodes associados a $I$. carnea subs. fistulosa diferiram nas duas áreas, no que diz respeito à diversidade, composição e abundância, em relação aos grupos tróficos. De modo que, na área preservada houveram herbívoros, predadores, e parasitoides, enquanto em área urbana (Tabela 4) não houve registro de parasitoides.

Para a área preservada, um total de 4.180 indivíduos de insetos herbívoros foram coletados e estes estão distribuídos em duas ordens, Coleoptera e Hemiptera, pertencentes a 14 famílias (Tabela 4).

Tabela 4. Distribuição em guildas, e frequência de herbívoros florais e foliares registrados em Ipomoea carnea subs. fistulosa em duas áreas de Caatinga no Nordeste do Brasil. AP = área preservada; $\mathrm{AU}=$ área urbana; $\mathrm{N}$ $=$ abundância $; \mathrm{F}=$ frequência, $\mathrm{G}=$ guilda .

\begin{tabular}{|c|c|c|c|c|c|c|c|}
\hline \multirow[b]{2}{*}{ Ordem/Família } & \multicolumn{3}{|c|}{$\mathbf{A P}$} & \multicolumn{3}{|c|}{$\mathbf{A U}$} & \multirow[b]{2}{*}{ Categoria } \\
\hline & $\mathbf{N}$ & F\% & G\% & $\mathbf{N}$ & $\mathbf{F} \%$ & G\% & \\
\hline \multicolumn{8}{|l|}{ Hymenoptera/Apidae } \\
\hline Apis melifera & 43 & 75,0 & 10,99 & 10 & 75,0 & 10,98 & Polinizador \\
\hline Pseudoaugochlora sp. & 5 & 50,0 & 1,27 & 0 & 0 & 0 & Polinizador \\
\hline Megachile sp1 & 4 & 25,0 & 1,02 & 0 & 0 & 0 & Polinizador \\
\hline Habralictus sp1 & 19 & 50,0 & 4,85 & 0 & 0 & 0 & Polinizador \\
\hline Habralictus sp2 & 2 & 12,5 & 0,51 & 0 & 0 & 0 & Polinizador \\
\hline Megachilinae sp1 & 6 & 37,5 & 1,53 & 0 & 0 & 0 & Polinizador \\
\hline Megachilinae sp2 & 6 & 37,5 & 1,53 & 0 & 0 & 0 & Polinizador \\
\hline Megachilinae sp3 & 1 & 12,5 & 0,25 & 0 & 0 & 0 & Polinizador \\
\hline Megachilinae sp4 & 2 & 25,0 & 0,51 & 2 & 12,5 & 2,19 & Polinizador \\
\hline Megachilinae sp5 & 37 & 50,0 & 9,46 & 24 & 75,0 & 26,37 & Polinizador \\
\hline
\end{tabular}




\begin{tabular}{|c|c|c|c|c|c|c|c|}
\hline Megachilinae sp6 & 31 & 87,5 & 7,92 & 7 & 75,0 & 7,69 & Polinizador \\
\hline Panurginae sp1 & 9 & 37,5 & 2,30 & 0 & 0 & 0 & Polinizador \\
\hline Panurginae sp2 & 5 & 37,5 & 1,27 & 0 & 0 & 0 & Polinizador \\
\hline Oragapostemon sp1 & 2 & 12,5 & 0,51 & 2 & 25,0 & 2,19 & Polinizador \\
\hline Megachile sp2 & 13 & 50,0 & 3,32 & 1 & 12,5 & 1,09 & Polinizador \\
\hline Xylocopa frontalis & 11 & 75,0 & 2,81 & 2 & 25,0 & 2,19 & Polinizador \\
\hline Augochlora sp1 & 1 & 12,5 & 0,25 & 0 & 0 & 0 & Polinizador \\
\hline Panurginae sp3 & 3 & 25,0 & 0,76 & 0 & 0 & 0 & Polinizador \\
\hline Megachilinae sp7 & 2 & 25,0 & 0,51 & 0 & 0 & 0 & Polinizador \\
\hline Habralictus sp3 & 1 & 12,5 & 0,25 & 0 & 0 & 0 & Polinizador \\
\hline Paroxystoglossa $\mathrm{sp} 1$ & 3 & 25,0 & 0,76 & 0 & 0 & 0 & Polinizador \\
\hline Megachile sp2 & 1 & 12,5 & 0,25 & 0 & 0 & 0 & Polinizador \\
\hline Megachilinae sp8 & 4 & 37,5 & 1,02 & 0 & 0 & 0 & Polinizador \\
\hline Paroxystoglossa $\mathrm{sp} 2$ & 1 & 12,5 & 0,25 & 0 & 0 & 0 & Polinizador \\
\hline Megachilinae sp10 & 2 & 12,5 & 0,51 & 0 & 0 & 0 & Polinizador \\
\hline Megachilinae sp11 & 1 & 12,5 & 0,25 & 0 & 0 & 0 & Polinizador \\
\hline Apinae sp & 1 & 12,5 & 0,25 & 2 & 25,0 & 2,19 & Polinizador \\
\hline Megachilinae sp9 & 1 & 12,5 & 0,25 & 0 & 0 & 0 & Polinizador \\
\hline \multicolumn{8}{|l|}{ Diptera/Muscidae } \\
\hline Muscidae sp1 & 4 & 37,5 & 1.02 & 3 & 25,0 & 3,29 & Pilhador \\
\hline Muscidae sp2 & 1 & 12,5 & 0,25 & 0 & 0 & 0 & Pilhador \\
\hline Muscidae sp3 & 1 & 12,5 & 0,25 & 0 & 0 & 0 & Pilhador \\
\hline Muscidae sp4 & 1 & 12,5 & 0,25 & 0 & 0 & 0 & Pilhador \\
\hline Muscidae sp5 & 5 & 37,5 & 1,27 & 3 & 37,5 & 3,29 & Pilhador \\
\hline Muscidae sp6 & 5 & 37,5 & 1,27 & 3 & 37,5 & 3,29 & Pilhador \\
\hline Muscidae sp7 & 3 & 37,5 & 0,76 & 2 & 25,0 & 2,19 & Pilhador \\
\hline Muscidae sp8 & 2 & 37,5 & 0,51 & 1 & 12,5 & 1,09 & Pilhador \\
\hline Muscidae sp9 & 6 & 37,5 & 1,53 & 2 & 25,0 & 2,19 & Pilhador \\
\hline Muscidae sp10 & 8 & 37,5 & 2.78 & 3 & 12,5 & 3,29 & Pilhador \\
\hline Muscidae sp11 & 2 & 12,5 & 0,51 & 2 & 12,5 & 2,19 & Pilhador \\
\hline Muscidae sp12 & 3 & 12,5 & 0,76 & 3 & 12,5 & 3,29 & Pilhador \\
\hline Muscidae sp13 & 6 & 12,5 & 1,53 & 6 & 12,5 & 6,59 & Pilhador \\
\hline Muscidae sp14 & 2 & 25,0 & 0,51 & 2 & 25,0 & 2,19 & Pilhador \\
\hline Muscidae sp15 & 3 & 12,5 & 0,76 & 1 & 12,5 & 1,09 & Pilhador \\
\hline Muscidae sp16 & 1 & 12,5 & 0,25 & 0 & 0 & 0 & Pilhador \\
\hline Muscidae sp17 & 1 & 12,5 & 0,25 & 0 & 0 & 0 & Pilhador \\
\hline Muscidae sp18 & 4 & 12,5 & 1.02 & 2 & 25,0 & 2,19 & Pilhador \\
\hline Muscidae sp19 & 12 & 12,5 & 3.07 & 8 & 25,0 & 8,79 & Pilhador \\
\hline \multicolumn{8}{|l|}{ Syrphidae } \\
\hline$\overline{\text { Syrphidae }}$ sp 1 & 12 & 62,5 & 3.07 & 0 & 0 & 0 & Pilhador \\
\hline Syrphidae sp 2 & 1 & 12,5 & 0,25 & 0 & 0 & 0 & Pilhador \\
\hline Syrphidae sp 3 & 2 & 12,5 & 0,51 & 0 & 0 & 0 & Pilhador \\
\hline Syrphidae sp 4 & 1 & 12,5 & 0,25 & 0 & 0 & 0 & Pilhador \\
\hline Syrphidae sp 5 & 1 & 12,5 & 0,25 & 0 & 0 & 0 & Pilhador \\
\hline Total & 391 & & & 91 & & & \\
\hline
\end{tabular}

A ordem Coleoptera foi a mais representativa em abundância e riqueza de espécies, correspondendo a 92,92\% dos herbívoros amostrados e dentro da ordem se destacou a família Chrysomelidae com 42 espécies e 3.033 indivíduos (Tabela 4). Dentre as guildas de herbívoros, 98,32\% foram mastigadores e apenas 5,93\% foram sugadores. As espécies mais abundantes foram Diabrotica speciosa $(\mathrm{n}=1.358), \quad$ Charidotella sexpunctata $(\mathrm{n}=1.372)$ e Conotelus $\mathrm{sp} .(\mathrm{n}=975)$ (Tabela 4). Com relação a frequência das espécies,
Bothrotes canaliculatus $(87,5 \%)$, D. speciosa (100\%), Psylliodes sp. 4 (75\%), C. sexpunctata (100\%) e Conotelus sp. (75\%) foram consideradas constantes. Para a área urbana foi registrado um total de 743 indivíduos distribuídos entre as ordens Coleoptera e Hemiptera, pertencentes a sete famílias, das quais três destas famílias foram de coleópteras e as demais de hemípteras. Em termos de abundância a ordem Coleoptera foi a mais representativa também com destaque para a família Chrysomelidae com 13 espécies e 578 indivíduos 
(Tabela 4). Diabrotica speciosa foi a espécie mais abundante $(\mathrm{n}=501)$, seguida de Conotelus sp. $(\mathrm{n}=150)$, e ambas foram consideradas constantes no que diz respeito a frequência $(75 \%)$, ao longo do período de amostragem, seguidas de Acanthoscelides obtectus e Bruchinae sp. 4 $(62,5 \%)$, também constantes. Houve influência da sazonalidade sobre a abundância de herbívoros (foliar e floral) $(\mathrm{F}=9,62, \mathrm{p}=0,02)$, com maior abundância nos meses com baixa precipitação
(Figura 2) para a área preservada, porém para a área urbana não houve correlação entre a abundância geral de herbívoros e precipitação pluviométrica $(\mathrm{F}$ $=3,65, \mathrm{p}=0,10)$, de modo que nos meses com menor precipitação ocorreram as maiores abundâncias de herbívoros. Porém, considerando a área urbana, houve uma relação inversa entre a abundância de herbívoros foliares e a precipitação $(\mathrm{F}=7,13, \mathrm{p}=0,04)$, havendo maior abundância nos meses com menor incidência de chuvas (Figura 3).

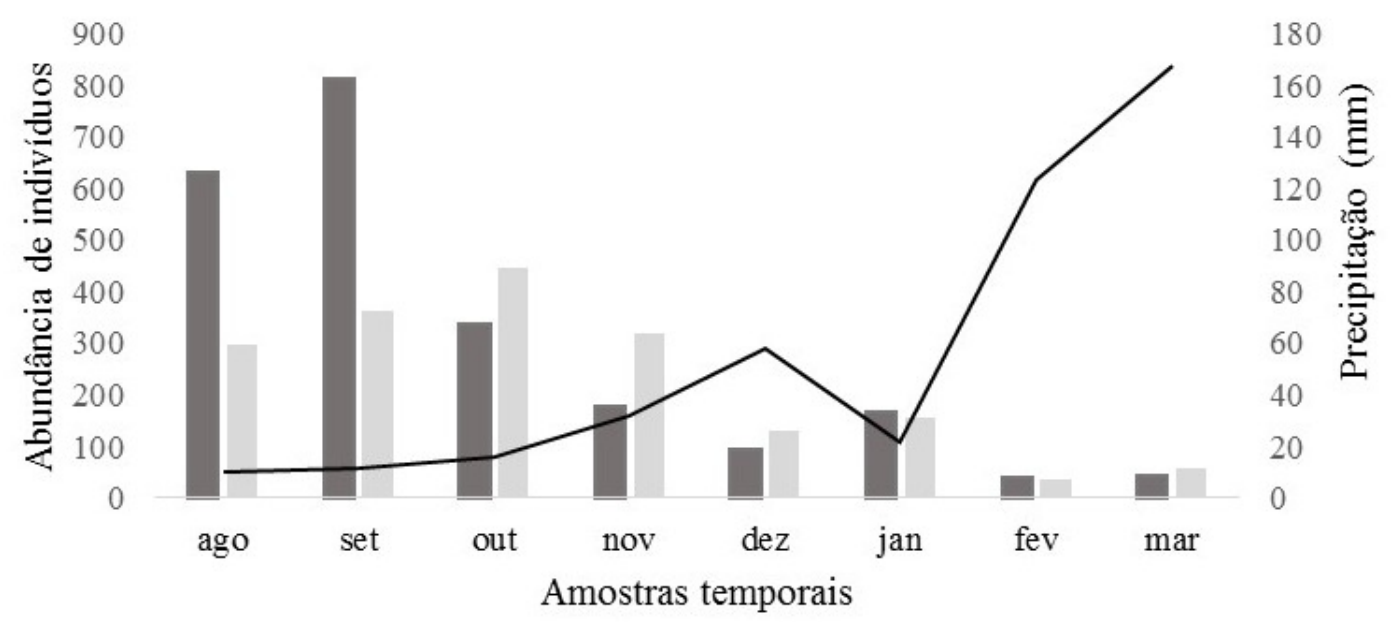

Herbívoros florais Herbívoros foliares — Precipitação pluviométrica(mm)

Figura 2. Abundância de herbívoros e precipitação pluviométrica durante o período de amostragem na área preservada, Santa Terezinha, Paraíba, Brasil.

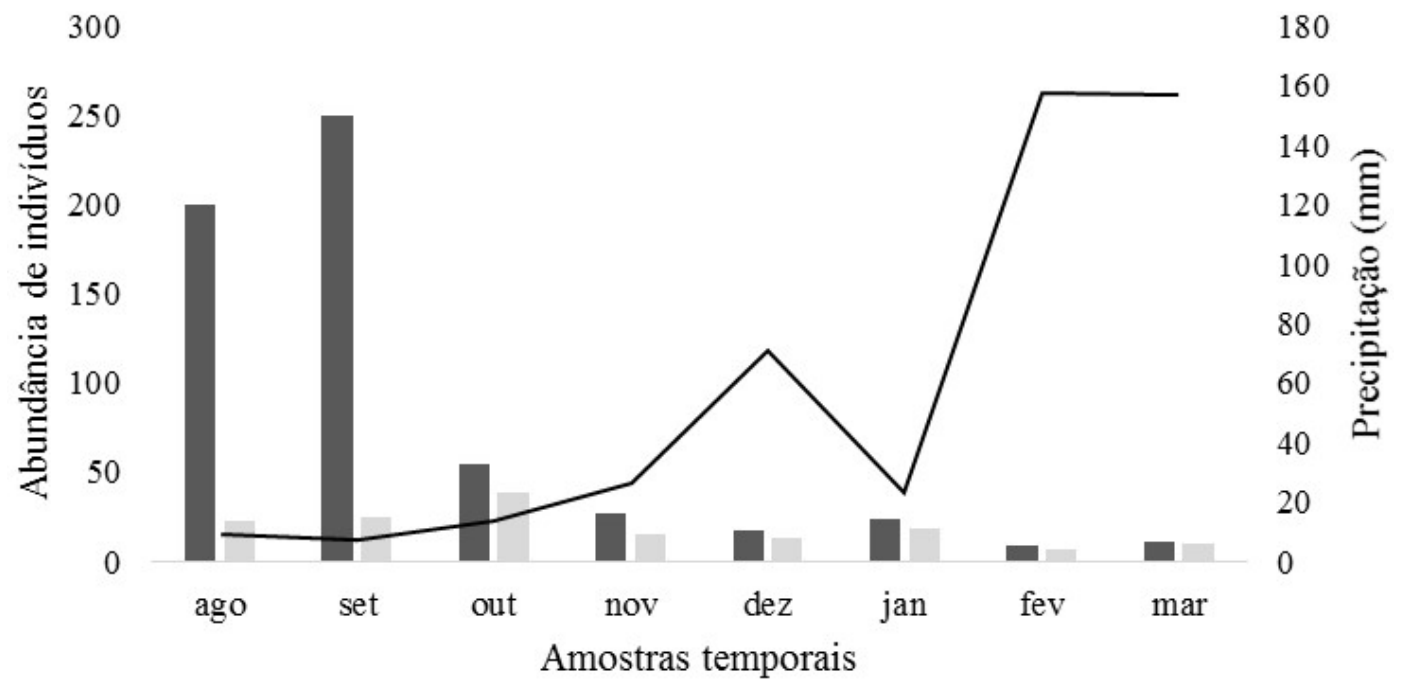

Herbívoros florais Herbívoros foliares — Precipitação Pluviométrica (mm)

Figura 3. Abundância de herbívoros e precipitação pluviométrica durante o período de amostragem na área urbana, Patos, Paraíba, Brasil.

\section{Visitantes florais}

A composição da fauna de visitantes florais amostrada ambas as áreas de estudo foram representadas por dois grupos de insetos pertencentes às ordens Hymenoptera e Diptera.
Para a área preservada, durante o período de estudo, foi registrado um total de 391 indivíduos, correspondendo a duas ordens (Hymenoptera $=28$ espécies; Diptera $=24$ espécies), três famílias e 52 espécies, sendo Hymenoptera a mais representativa em riqueza de 
espécies, com 59,57\%, representada apenas por espécies de abelhas. As espécies Megachilinae sp. $6(\mathrm{~F}=87,5 \%)$ e Apis melifera $(\mathrm{F}=75 \%)$ foram categorizadas como constantes (Tabela 5). Quanto ao modo de coleta de recursos florais, todos os dípteros acessaram o néctar floral por vias ilegítimas, sendo, portanto, classificados como pilhadores, e todos os himenópteros foram classificados como polinizadores.

Tabela 5. Visitantes florais da ordem Hymenoptera em Ipomoea carnea subs. fistulosa em duas áreas de caatinga no Nordeste do Brasil. AP = área preservada; $\mathrm{AU}=$ área urbana; $\mathrm{N}=$ Abundância; $\mathrm{F}=$ frequência, $\mathrm{G}$ = guilda.

\begin{tabular}{|c|c|c|c|c|c|c|c|}
\hline \multirow{2}{*}{ Ordem/Família } & \multicolumn{3}{|c|}{$\mathbf{A P}$} & \multicolumn{3}{|c|}{$\mathbf{A} \mathbf{U}$} & \multirow{2}{*}{ Categoria } \\
\hline & $\mathbf{N}$ & $\mathbf{F} \%$ & $\mathbf{G} \%$ & $\mathbf{N}$ & $\mathbf{F} \%$ & $\mathrm{G} \%$ & \\
\hline \multicolumn{8}{|l|}{ Hymenoptera/Apidae } \\
\hline Apis melifera & 43 & 75,0 & 10,99 & 10 & 75 & 10,98 & Polinizador \\
\hline Pseudoaugochlora sp & 5 & 50,0 & 1,27 & 0 & 0 & 0 & Polinizador \\
\hline Megachile sp1 & 4 & 25,0 & 1,02 & 0 & 0 & 0 & Polinizador \\
\hline Habralictus sp1 & 19 & 50,0 & 4,85 & 0 & 0 & 0 & Polinizador \\
\hline Habralictus sp2 & 2 & 12,5 & 0,51 & 0 & 0 & 0 & Polinizador \\
\hline Megachilinae sp1 & 6 & 37,5 & 1,53 & 0 & 0 & 0 & Polinizador \\
\hline Megachilinae sp2 & 6 & 37,5 & 1,53 & 0 & 0 & 0 & Polinizador \\
\hline Megachilinae sp3 & 1 & 12,5 & 0,25 & 0 & 0 & 0 & Polinizador \\
\hline Megachilinae sp4 & 2 & 25,0 & 0,51 & 2 & 12,5 & 2,19 & Polinizador \\
\hline Megachilinae sp5 & 37 & 50,0 & 9,46 & 24 & 75,0 & 26,37 & Polinizador \\
\hline Megachilinae sp6 & 31 & 87,5 & 7,92 & 7 & 75,0 & 7,69 & Polinizador \\
\hline Panurginae sp1 & 9 & 37,5 & 2,30 & 0 & 0 & 0 & Polinizador \\
\hline Panurginae sp2 & 5 & 37,5 & 1,27 & 0 & 0 & 0 & Polinizador \\
\hline Oragapostemon sp1 & 2 & 12,5 & 0,51 & 2 & 25,0 & 2,19 & Polinizador \\
\hline Megachile sp2 & 13 & 50,0 & 3,32 & 1 & 12,5 & 1,09 & Polinizador \\
\hline Xylocopa frontalis & 11 & 75,0 & 2,81 & 2 & 25,0 & 2,19 & Polinizador \\
\hline Augochlora sp1 & 1 & 12,5 & 0,25 & 0 & 0 & 0 & Polinizador \\
\hline Panurginae sp3 & 3 & 25,0 & 0,76 & 0 & 0 & 0 & Polinizador \\
\hline Megachilinae sp7 & 2 & 25,0 & 0,51 & 0 & 0 & 0 & Polinizador \\
\hline Habralictus sp3 & 1 & 12,5 & 0,25 & 0 & 0 & 0 & Polinizador \\
\hline Paroxystoglossa sp1 & 3 & 25,0 & 0,76 & 0 & 0 & 0 & Polinizador \\
\hline Megachile sp2 & 1 & 12,5 & 0,25 & 0 & 0 & 0 & Polinizador \\
\hline Megachilinae sp8 & 4 & 37,5 & 1,02 & 0 & 0 & 0 & Polinizador \\
\hline Paroxystoglossa sp2 & 1 & 12,5 & 0,25 & 0 & 0 & 0 & Polinizador \\
\hline Megachilinae sp10 & 2 & 12,5 & 0,51 & 0 & 0 & 0 & Polinizador \\
\hline Megachilinae sp11 & 1 & 12,5 & 0,25 & 0 & 0 & 0 & Polinizador \\
\hline Apinae sp & 1 & 12,5 & 0,25 & 2 & 25,0 & 2,19 & Polinizador \\
\hline Megachilinae sp9 & 1 & 12,5 & 0,25 & 0 & 0 & 0 & Polinizador \\
\hline \multicolumn{8}{|l|}{ Diptera/Muscidae } \\
\hline Muscidae sp1 & 4 & 37,5 & 1.02 & 3 & 25,0 & 3,29 & Pilhador \\
\hline Muscidae sp2 & 1 & 12,5 & 0,25 & 0 & 0 & 0 & Pilhador \\
\hline Muscidae sp3 & 1 & 12,5 & 0,25 & 0 & 0 & 0 & Pilhador \\
\hline Muscidae sp4 & 1 & 12,5 & 0,25 & 0 & 0 & 0 & Pilhador \\
\hline Muscidae sp5 & 5 & 37,5 & 1,27 & 3 & 37,5 & 3,29 & Pilhador \\
\hline Muscidae sp6 & 5 & 37,5 & 1,27 & 3 & 37,5 & 3,29 & Pilhador \\
\hline Muscidae sp7 & 3 & 37,5 & 0,76 & 2 & 25,0 & 2,19 & Pilhador \\
\hline Muscidae sp8 & 2 & 37,5 & 0,51 & 1 & 12,5 & 1,09 & Pilhador \\
\hline Muscidae sp9 & 6 & 37,5 & 1,53 & 2 & 25,0 & 2,19 & Pilhador \\
\hline Muscidae sp10 & 8 & 37,5 & 2.78 & 3 & 12,5 & 3,29 & Pilhador \\
\hline Muscidae sp11 & 2 & 12,5 & 0,51 & 2 & 12,5 & 2,19 & Pilhador \\
\hline Muscidae sp12 & 3 & 12,5 & 0,76 & 3 & 12,5 & 3,29 & Pilhador \\
\hline Muscidae sp13 & 6 & 12,5 & 1,53 & 6 & 12,5 & 6,59 & Pilhador \\
\hline Muscidae sp14 & 2 & 25,0 & 0,51 & 2 & 25,0 & 2,19 & Pilhador \\
\hline Muscidae sp15 & 3 & 12,5 & 0,76 & 1 & 12,5 & 1,09 & Pilhador \\
\hline Muscidae sp16 & 1 & 12,5 & 0,25 & 0 & 0 & 0 & Pilhador \\
\hline Muscidae sp17 & 1 & 12,5 & 0,25 & 0 & 0 & 0 & Pilhador \\
\hline Muscidae sp18 & 4 & 12,5 & 1.02 & 2 & 25,0 & 2,19 & Pilhador \\
\hline
\end{tabular}




\begin{tabular}{lccccccc}
\hline Muscidae sp19 & 12 & 12,5 & 3.07 & 8 & 25,0 & 8,79 & Pilhador \\
Syrphidae & & & & & & & Pilhador \\
Syrphidae sp 1 & 12 & 62,5 & 3.07 & 0 & 0 & 0 & Pilhador \\
Syrphidae sp 2 & 1 & 12,5 & 0,25 & 0 & 0 & 0 & Pilhador \\
Syrphidae sp 3 & 2 & 12,5 & 0,51 & 0 & 0 & 0 & Pilhador \\
Syrphidae sp 4 & 1 & 12,5 & 0,25 & 0 & 0 & 0 & Pilhador \\
Syrphydae sp 5 & 1 & 12,5 & 0,25 & 0 & 0 & 0 & \\
TOTAL & 391 & & & & & & \\
\hline
\end{tabular}

Em relação à dominância das espécies amostradas foi observada somente uma espécie eudominante: A. mellifera (10,99\%), duas espécies dominantes: Megachilinae sp5 (9,46\%) e Megachilinae sp6 (7,92\%) e as espécies Habralictus sp1 (4,85\%), Panurginae sp1 (2,30\%), Xylocopa frontalis $(2,81 \%)$, Megachile $\mathrm{sp} 2$ (3,32\%), Muscidae sp10 (2,78\%), e Syrphidae sp 1 (3.07\%) foram categorizadas como subdominante. Assim, ocorreram poucas espécies subdominantes ou recessivas e o maior valor encontrado foi para as espécies raras, com $45 \%$ do total amostrado. A área urbana apresentou uma menor abundância $\mathrm{e}$ riqueza de visitantes florais com um total de 91 indivíduos $($ Hymenoptera $=50$; Diptera $=41)$ e 22 espécies $($ Hymenoptera $=8$; Diptera $=14)$, assim como para área preservada a ordem Hymenoptera foi representada apenas por abelhas, das quais Megachilinae sp5 (26,37\%) e A. melífera $(10,98 \%)$ foram eudominantes, e apenas Megachilinae sp6 $(7,69 \%)$ foi dominante, as demais foram subdominantes ou recessivas (Tabela 5). Para a área preservada a riqueza e a abundância de visitantes florais em geral foram maiores no período chuvoso, especialmente entre fevereiro e março, com a maior riqueza de espécies registrada no mês de fevereiro e a maior abundância de indivíduos em março de 2015 (Figuras 4 e 5).

A abundância (Regressão linear: $\mathrm{F}=5,93$, $\mathrm{p}=0,05)$ e riqueza mensal (Regressão Linear: $\mathrm{F}=$ $8,50, \mathrm{p}=0,02)$ de Hymenoptera variaram ao longo do período de amostragem conforme a precipitação pluviométrica. Para os dípteros a riqueza $(\mathrm{F}=0,05$, $\mathrm{p}=0,80)$ e abundância $(\mathrm{F}=0,18, \mathrm{p}=0,89)$ não variou conforme a precipitação pluviométrica.

Para a área urbana a riqueza e a abundância de visitantes florais em geral não diferiu muito entre o período chuvoso, porém as maiores abundâncias e riquezas ocorreram nos meses com menor precipitação em cada um dos períodos, assim para o período seco ocorreu uma maior abundância em setembro (precipitação $=7,51 \mathrm{~mm}$ ) e durante o período chuvoso a maior abundância de indivíduos ocorreu em janeiro (precipitação = 23,37 mm) de 2015 (Figura 5). Porém não houve relação significativa entre a abundância (Regressão linear: $F=0,07, p=0,79)$ e riqueza mensal (Regressão Linear: $\mathrm{F}=0,06, \mathrm{p}=0,79$ ) de visitantes florais e a precipitação pluviométrica.

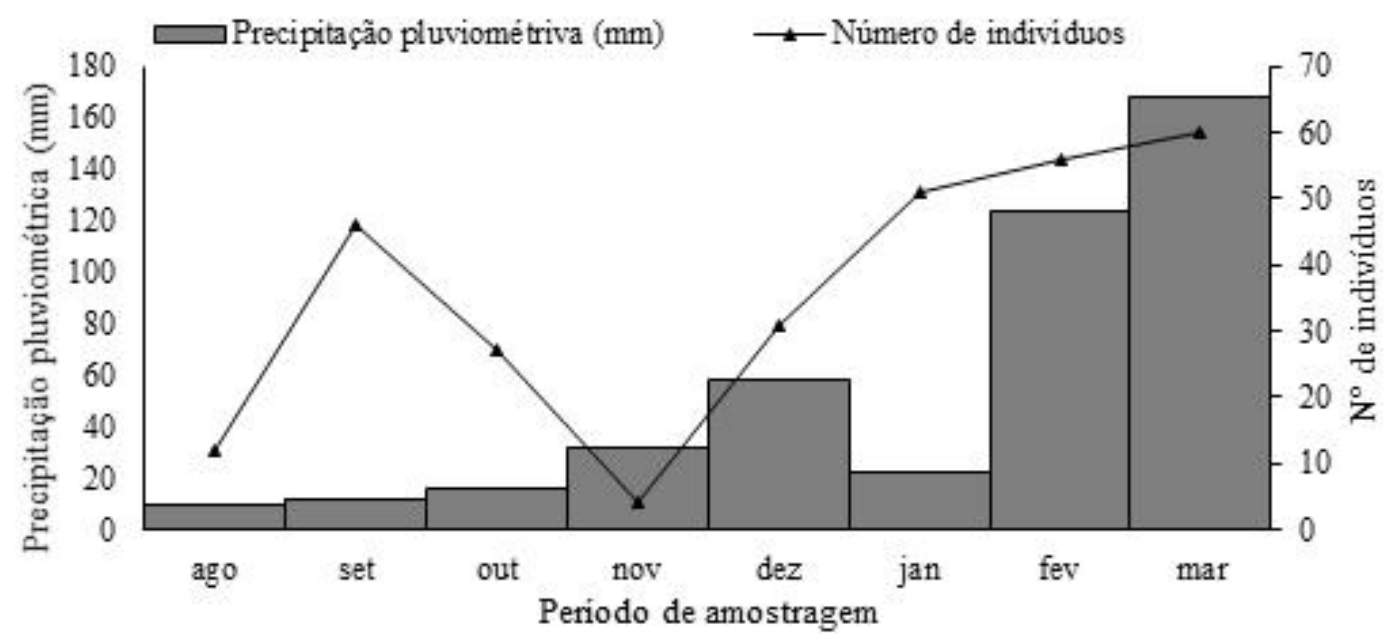

Figura 4. Abundância de visitantes florais associados a Ipomoea carnea subs. fistulosa e precipitação pluviométrica na área preservada (área de Caatinga, Santa Terezinha, Paraíba). 

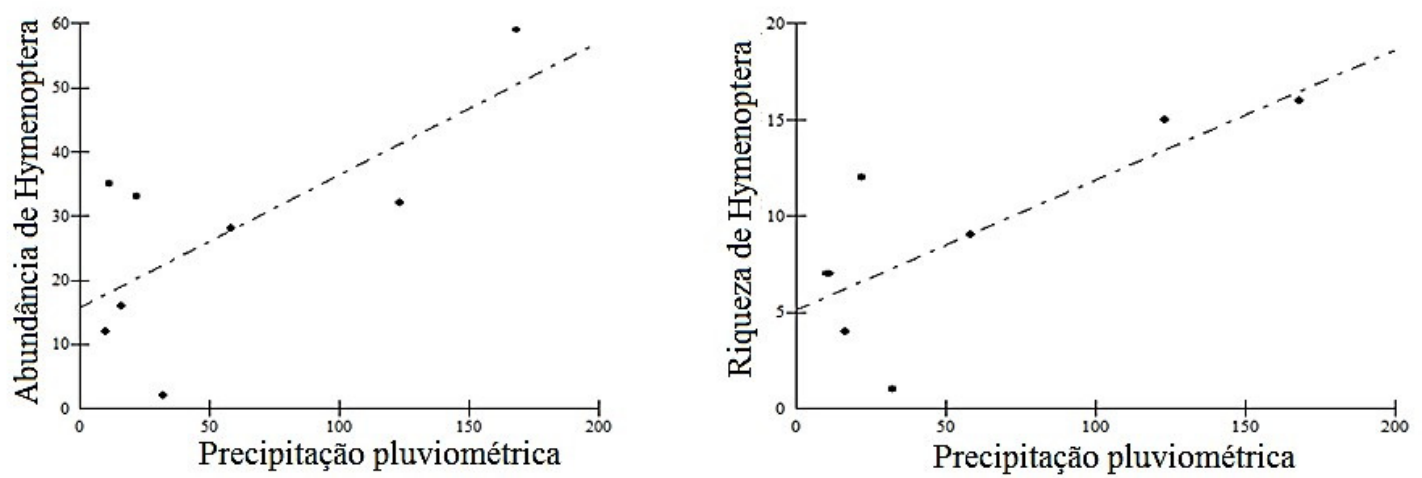

Figura 5. Regressão linear entre a abundância e riqueza de Hymenoptera visitantes florais de Ipomoea carnea subs. fistulosa e a precipitação pluviométrica na área preservada (área de Caatinga, Santa Terezinha, Paraíba).

\section{Predadores}

Para a área preservada foram coletados 3.313 artrópodes predadores nas inflorescências de Ipomoea carnea subs. fistulosa, distribuídas em cinco ordens: Hymenoptera, Coleoptera,
Hemiptera, Diptera e Araneae e 50 espécies/morfoespécies (Tabela 6). As mesmas ordens se repetiram para área urbana, com um total de 517 indivíduos e apenas 28 espécies (Tabela 6).

Tabela 6. Predadores associados a Ipomoea carnea susb. fistulosa em área duas áreas de caatinga, no Nordeste do Brasil.

\begin{tabular}{|c|c|c|c|c|c|}
\hline \multirow{2}{*}{ ORDEM/ FAMÍLIA } & \multicolumn{2}{|c|}{ AP } & \multicolumn{2}{|c|}{$\mathbf{A U}$} & \multirow{2}{*}{ GUILDA } \\
\hline & $\mathbf{N}$ & F\% & $\mathbf{N}$ & $\mathrm{F} \%$ & \\
\hline \multicolumn{6}{|l|}{ HYMENOPTERA-FORMICIDAE } \\
\hline Formicinae-Camponotus crassus & 356 & 100 & 167 & 100 & M \\
\hline Camponotus sp.1 & 58 & 62,5 & 17 & 37,5 & M \\
\hline Camponotus sp.2 & 5 & 50 & 2 & 25 & M \\
\hline Camponotus sp. 3 & 17 & 62,5 & 5 & 37,5 & M \\
\hline Camponotus sp.4 & 5 & 50 & 5 & 50 & M \\
\hline Camponotus sp.5 & 3 & 25 & 3 & 12,5 & M \\
\hline Brachymyrmex sp.1 & 5 & 25 & 0 & 0 & M \\
\hline Myrmicinae-Solenopsis sp.1 & 207 & 75 & 150 & 100 & M \\
\hline Crematogaster sp. 1 & 3 & 37,5 & 0 & 0 & M \\
\hline Cephalotes pusillus & 13 & 37,5 & 0 & 0 & M \\
\hline Solenopsis sp.2 & 1 & 12,5 & 1 & 12,5 & M \\
\hline Solenopsis sp.3 & 1 & 12,5 & 1 & 12,5 & M \\
\hline Dolichoderinae-Dorymyrmex sp.1 & 69 & 75 & 18 & 75 & M \\
\hline Dorymyrmex sp.2 & 67 & 75 & 17 & 87,5 & M \\
\hline Pseudomyrmecinae-Pseudomyrmex sp. 1 & 4 & 37,5 & 1 & 12,5 & M \\
\hline \multicolumn{6}{|l|}{ HYMENOPTERA NÃO-FORMICIDAE } \\
\hline Vespidae-Zeta sp. & 73 & 100 & 16 & 100 & $\mathrm{~T}$ \\
\hline Polybia ignobilis & 29 & 75 & 18 & 100 & $\mathrm{~T}$ \\
\hline Polybia sp.2 & 29 & 37,5 & 1 & 37,5 & $\mathrm{~T}$ \\
\hline Polybia sp.1 & 63 & 75 & 4 & 100 & $\mathrm{~T}$ \\
\hline Eumeninae sp.1 & 32 & 75 & 16 & 87,5 & $\mathrm{~T}$ \\
\hline Chalcididae-Conura sp.1 & 10 & 37,5 & 0 & 0 & $\mathrm{P}$ \\
\hline Pompilidae- Epipompilus sp.1 & 3 & 25 & 0 & 0 & $\mathrm{P}$ \\
\hline
\end{tabular}




\begin{tabular}{|c|c|c|c|c|c|}
\hline Coccinelidae-Hippodamia convergens & 13 & 50 & 8 & 37,5 & $\mathrm{M}$ \\
\hline Coccinelidae sp. 1 & 13 & 50 & 0 & 0 & M \\
\hline Coccinelidae sp. 2 & 16 & 62,5 & 0 & 0 & M \\
\hline Psyllobora sp. & 23 & 37,5 & 10 & 37,5 & M \\
\hline Coleomegilla maculata & 106 & 87,5 & 25 & 12,5 & M \\
\hline Coccinelidae sp. 3 & 3 & 37,5 & 3 & 37,5 & M \\
\hline Cycloneda sanguínea & 2 & 12,5 & 0 & 12,5 & M \\
\hline \multicolumn{6}{|l|}{ HEMIPTERA } \\
\hline Geocoridae-Geocoridae sp & 1 & 12,5 & 0 & 0 & PS \\
\hline Nabidae-Nabidae sp & 2 & 12,5 & 0 & 0 & PS \\
\hline Reduviidae-Reduviidae sp.1 & 4 & 37,5 & 0 & 0 & PS \\
\hline Reduviidae sp.2 & 1 & 12,5 & 2 & 25 & PS \\
\hline Reduviidae sp.3 & 14 & 37,5 & 0 & 0 & PS \\
\hline \multicolumn{6}{|l|}{ ARANEAE } \\
\hline Anyphaenide-Anyphaenide sp. & 1 & 12,5 & 0 & 0 & TSL \\
\hline Araneidae-Eriophora edax & 1 & 12,5 & 0 & 0 & TSL \\
\hline Oxyopidae-Peucetia sp. & 1 & 12,5 & 0 & 0 & TSL \\
\hline Pisauridae-Pisauridae sp. & 2 & 12,5 & 0 & 0 & TSL \\
\hline Thomisidae-Misumenops pallidus & 36 & 100 & 7 & 50 & TSL \\
\hline Misumenops pallens & 7 & 25 & 5 & 37,5 & TSL \\
\hline Salticidae-Salticidae sp.1 & 2 & 25 & 0 & 0 & TSL \\
\hline Salticidae sp.2 & 5 & 50 & 0 & 0 & TSL \\
\hline Salticidae sp.3 & 3 & 37,5 & 0 & 0 & TSL \\
\hline Salticidae sp.4 & 1 & 25 & 0 & 0 & TSL \\
\hline Salticidae sp.5 & 3 & 25 & 3 & 37,5 & TSL \\
\hline \multicolumn{6}{|l|}{ DIPTERA } \\
\hline Asilidae-Asilinae sp.1 & 2 & 12,5 & 9 & 50 & PS \\
\hline TOTAL & 1319 & & 517 & & \\
\hline
\end{tabular}

*AP: área preservada; AU: área urbana N: Abundância; F: frequência, D: dominância; G: guilda; M: mastigador; T: triturador; P: parasitoide; PS: picador-sugador; TSL: triturador-sugador-lambedor.

Hymenoptera foi a ordem mais representativa em abundância e riqueza, de modo que para a área preservada apresentou $79,89 \%$ de indivíduos coletados e $48 \%$ das espécies registradas, e para a área urbana representou $86,07 \%$ dos indivíduos amostrados e $67,85 \%$ das espécies registradas.

Para o total de 1049 himenópteros coletados para a área preservada, 821 foram Hymenoptera Formicidae (formigas) e 228 Hymenoptera não Formicidae (vespas). Considerando a área urbana, um total de 445 himenópteros foram registrados, dos quais 390 Hymenoptera Formicidae e 55 Hymenoptera não Formicidae (vespas). Todos os himenópteros foram coletados forrageando em nectários extraflorais (na base das flores), as aranhas e hemípteros foram coletadas sobre as flores (na corola), os coleópteros foram coletados forrageando nos botões florais, e os dípteros nas folhas.

As espécies mais abundantes foram Camponotus crassus (Área 1= 356; Área $2=167$ ), Solenopsis sp.1 (Área $1=207$; Área $2=150$ ) e Coleomegilla maculata (Área preservada $=106$; área urbana=25) para ambas as áreas, sendo que na área preservada as três espécies foram bem mais abundantes.

Com relação a frequência para a área preservada foram categorizadas como constantes, as morfoespécies da família Formicidae 
(Hymenoptera): C. crassus $(\mathrm{F}=100 \%)$, Solenopsis sp.1 (75\%), Dorymyrmex sp.1 (75\%), Dorymyrmex sp.2 (75\%), Camponotus sp.1 (62,5\%) $e$ Camponotus sp.3 (62,5\%); da família Vespidae (Hymenoptera): Polybia ignobilis (75\%), Polybia sp.1 (75\%) e Eumeninae sp.1 (75\%); da família Coccinelidade (Coleoptera): Coleomegilla maculata (87\%) e Coccinelidae sp.2 (62,5\%): e da família Thomisidae (Araneae): Misumenops pallidus (100\%). Para a área urbana foram categorizadas como constantes as morfoespécies da família Formicidae (Hymenoptera): C. crassus $(\mathrm{F}=100 \%)$, Solenopsis sp.1 (100\%), Dorymyrmex sp.2 (87,5\%); da família Vespidae (Hymenoptera):
Zeta sp1 (100\%), P. ignobilis (100\%), Eumeninae sp.1 (87,5). A frequência das demais espécies está disposta na Tabela 6.

As maiores abundâncias e riqueza de predadores ocorreram nos meses com baixa precipitação, entre agosto e outubro de 2014 (Figura 6). No entanto, a maior riqueza registrada durante o período de amostragem ocorreu no mês de maior precipitação pluviométrica, em março de 2015. Entretanto, não houve relação significativa entre a abundância e a precipitação mensal (Regressão linear: $\mathrm{F}=3,51 ; \mathrm{p}=0,11$ ), bem como entre riqueza e precipitação mensal (Regressão linear: $\mathrm{F}=1,53 ; \mathrm{p}=0,26)$ para a área preservada.

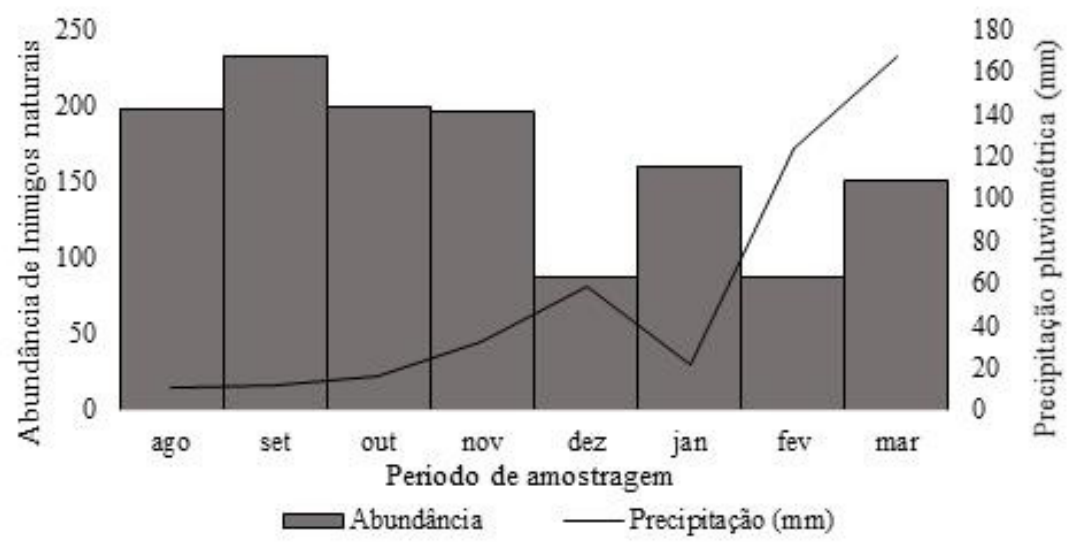

Figura 6. Variação da abundância de predadores associados a Ipomoea carnea subs. fistulosa e precipitação pluviométrica ao longo do período de amostragem na área preservada (área de caatinga, Santa Terezinha, Paraíba, Brasil).

Considerando a área urbana, houve correlação entre a abundância de inimigos naturais (insetos predadores) e a precipitação pluviométrica (Regressão linear: $\mathrm{F}=6,22 ; \mathrm{p}=0,04$ ) (Figuras 7 e
8) com maior abundância nos meses com baixa precipitação, não havendo, também, relação significativa entre a precipitação e a riqueza de espécies (Regressão linear: $\mathrm{F}=0.31, \mathrm{p}=0.59$ ).

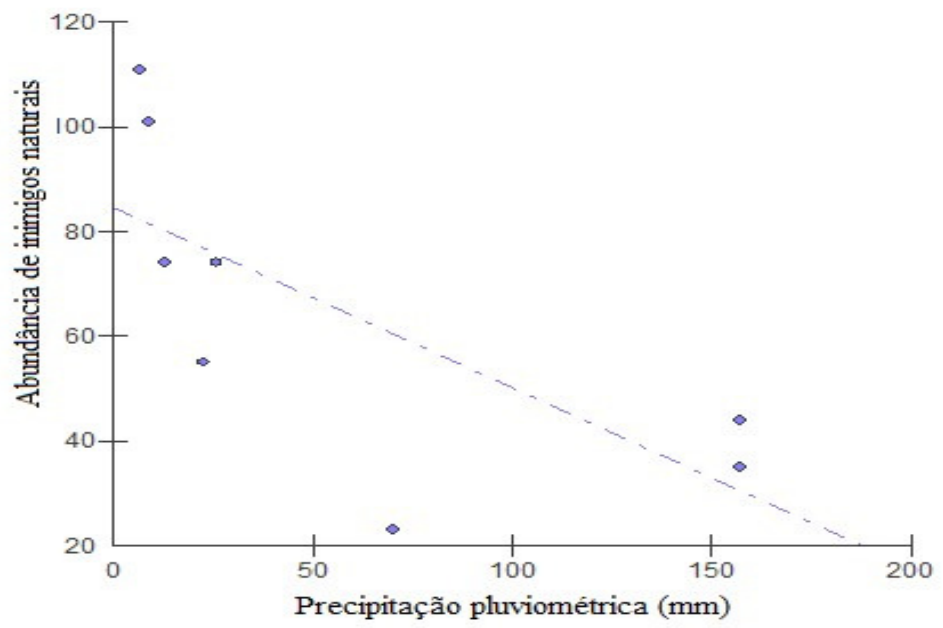

Figura 7. Relação entre a precipitação pluviométrica e abundância de inimigos naturais de agosto de 2014 a março de 2015 em área urbana (área de Caatinga, Patos, Paraíba, Brasil). 


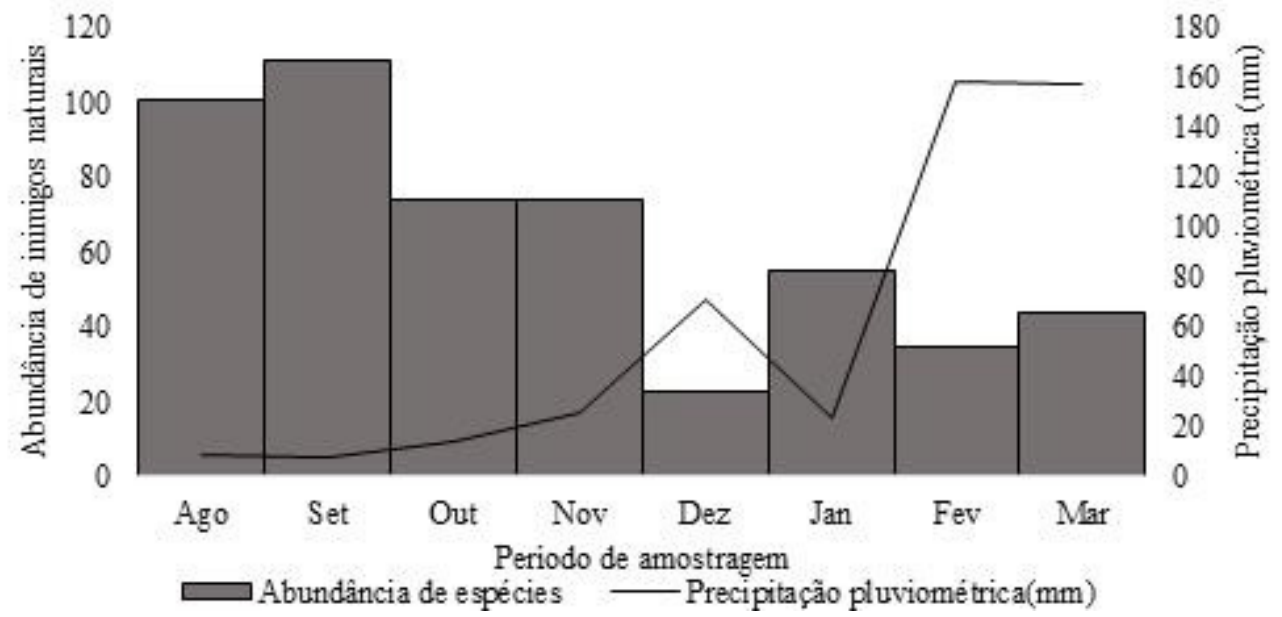

Figura 8. Abundância de inimigos naturais associados a Ipomoea carnea subs. fistulosa em área urbana (área de caatinga, Patos, Paraíba, Brasil).

\section{Relação entre todos os níveis tróficos}

Considerando a área preservada, a abundância mensal de predadores variou conforme a abundância de herbívoros em geral (Regressão Linear: $\mathrm{F}=16,07 ; \mathrm{p}=0,01$ ) (Figura 9a), com maior número de indivíduos nos meses que apresentaram maior número de herbívoros. Quando analisados separadamente, dentre os predadores, apenas as

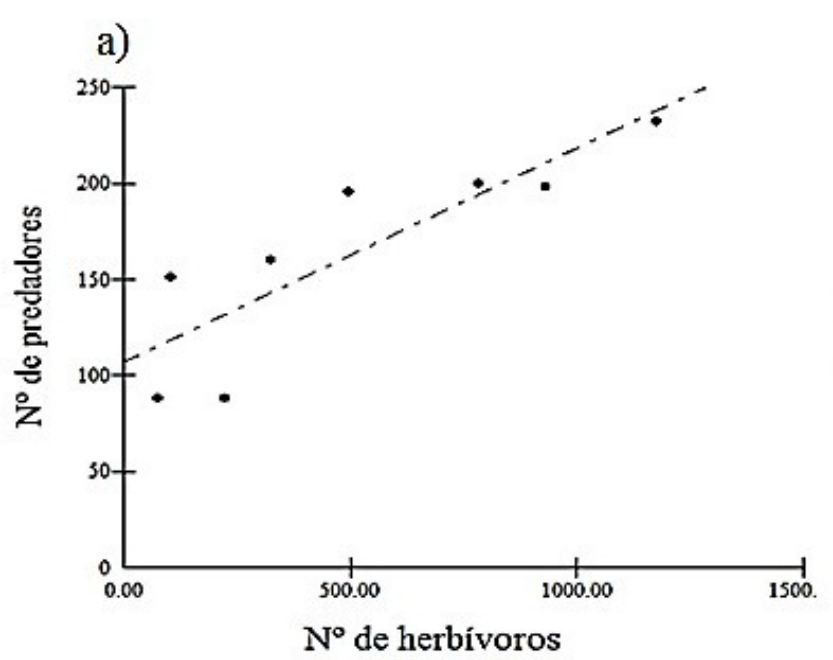

aranhas apresentaram maior abundância nos meses com as maiores abundâncias de polinizadores entre fevereiro e março. $\mathrm{O}$ número de formigas associadas a nectários extraflorais foi maior nos meses com maior abundância de herbívoros florais (Regressão Linear: $\mathrm{F}=18,51 ; \mathrm{p}=0,01$ ) (Figura 9b).

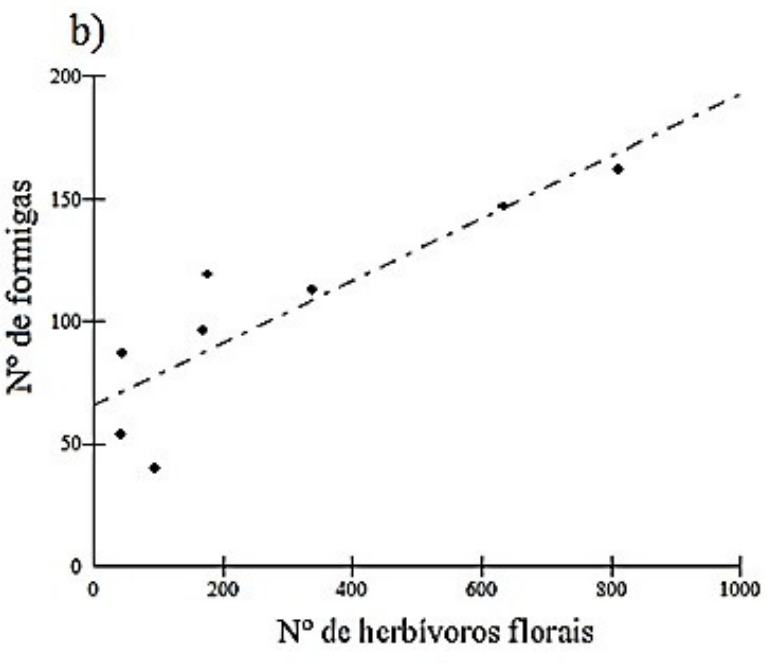

Figura 9. Variação na abundância de predadores conforme o número de presas na área preservada. a) Número de predadores em geral aumentando conforme como o aumento do número de herbívoros b) Número de formigas associadas a nectários extraflorais aumentando conforme o aumento do número de herbívoros florais.

Para a área urbana a abundância geral de predadores variou conforme a abundância de polinizadores e herbívoros (Regressão múltipla:
$\left.\mathrm{F}_{(2,5)}=11,06 ; \mathrm{p}=0,02\right)$. A distribuição dos grupos tróficos ao longo do período de estudos está disposta nas Figuras 10 e 11. 


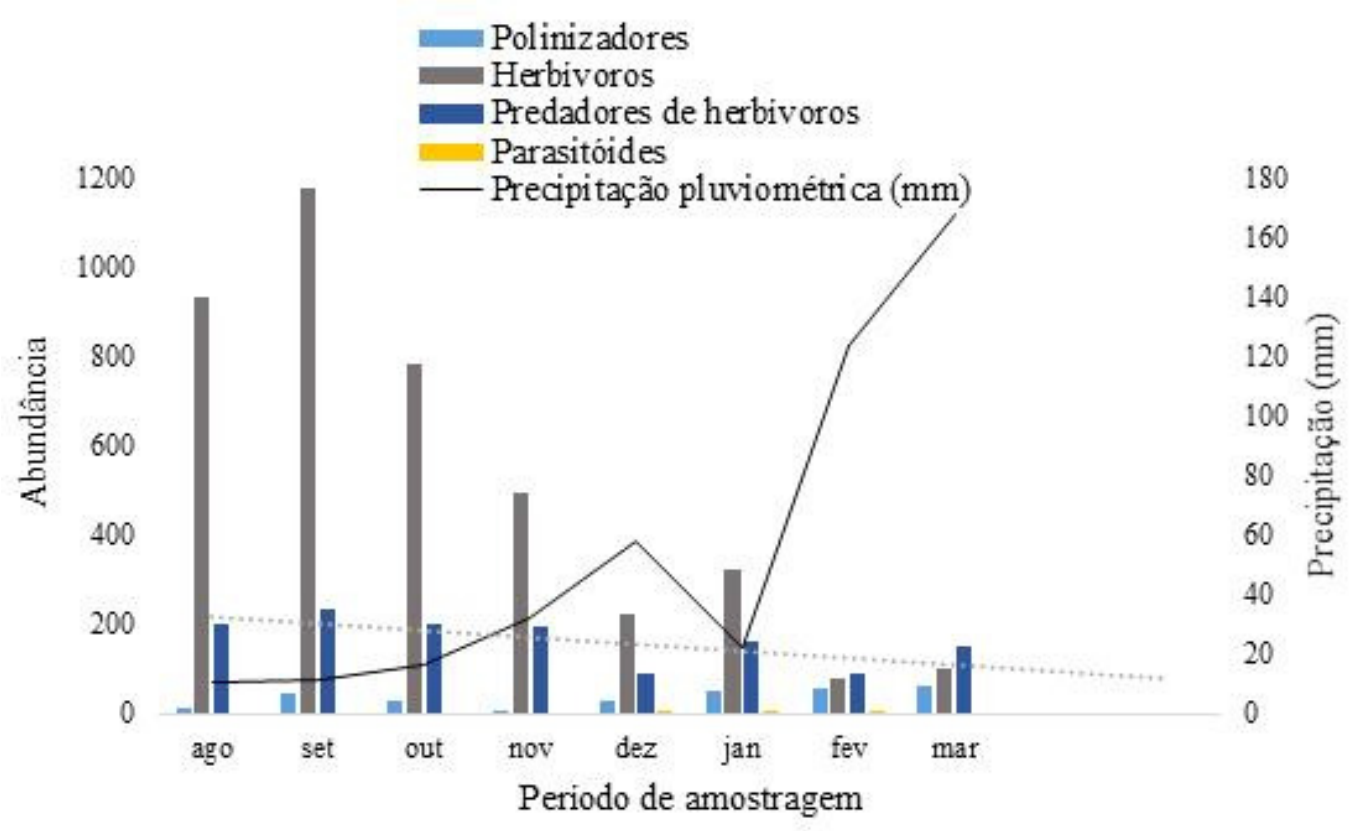

Figura 10. Variação temporal na abundância de predadores e precipitação pluviométrica na área preservada (área de Caatinga, Santa Terezinha, Paraíba, Brasil).

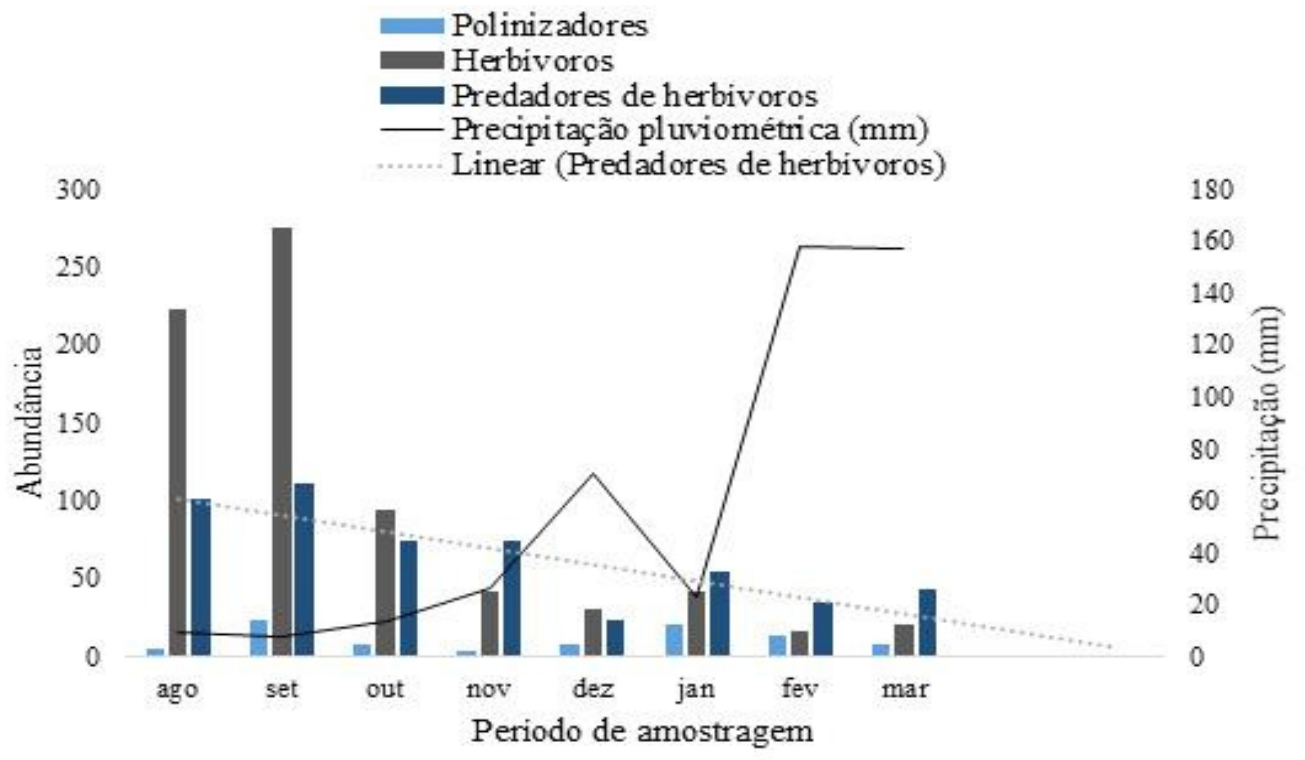

Figura 11. Variação temporal na abundância de predadores e precipitação pluviométrica em área urbana (área de Caatinga, Patos, Paraíba, Brasil).

\section{Discussão}

A fauna associada a Ipomoea carnea subs. fistulosa foi diferente em ambas as áreas em composição, riqueza e abundância de espécies. Deste modo, a área preservada apresentou uma significativa riqueza e abundância de espécies quando comparada à área urbana, o que pode ser um reflexo da preservação do ecossistema nestas áreas.

O sistema multitrófico estudado na área preservada mostrou-se bastante complexo, apresentando uma grande riqueza de artrópodes associados e variadas guildas dentre os níveis tróficos, de modo que, para esta área, foram registrados polinizadores, herbívoros, predadores e parasitoides. Enquanto que, para a área urbana, além de não haver registro de parasitoides, a abundância e riqueza nos demais níveis tróficos foram inferiores ao registrado para a área preservada.

A análise da abundância da fauna de visitantes florais amostrada evidenciou para a área preservada, um predomínio de espécies raras, ou seja, um número reduzido de espécies representado por um grande número de indivíduos e um elevado número de espécies com apenas um indivíduo. Padrão semelhante foi registrado por Lopes et al. (2007). Segundo Andena et al. (2005), esse padrão é esperado para amostragens realizadas em ecossistemas neotropicais. Lopes et al. (2007), em 
estudos com antófilos no Rio Grande do Sul, não registraram nenhuma espécie categorizada como eudominante ou dominante e semelhante a esse estudo, também amostraram um grande número de espécies raras. De acordo com Andena et al. (2009), fatores locais como interações entre populações, competição e interferência de áreas vizinhas podem influenciar e determinar a riqueza de espécies de abelhas em cada área.

Entre os visitantes florais da área preservada, praticamente todas as espécies foram de abelhas solitárias, representadas, principalmente, pela subfamília Megachilinae, a qual foi predominante, além da espécie Xylocopa frontalis da subfamília Xylocopinae, e representantes das subfamílias Panurginae e Halictinae, entre outras. Estas abelhas são especialistas e neste estudo atuaram como polinizadores efetivos. Os poucos estudos de caso que avaliam o papel das abelhas especializadas como polinizadores mostram que as abelhas envolvidas, em geral, são polinizadores efetivos, não substituíveis por abelhas generalistas. Desta maneira, estas abelhas especializadas, geralmente solitárias, possuem um papel importante na manutenção das espécies vegetais (Pacheco-Filho, 2015).

Para a área urbana, entre os visitantes florais não ocorreram espécies raras, e praticamente todas as espécies que foram raras para a área preservada, não ocorreram na área urbana. Além disso, dentre os visitantes florais para área urbana, a riqueza de espécies da ordem Diptera foi superior a riqueza de espécies de abelhas, com apenas oito espécies, das quais, duas espécies solitárias foram polinizadores efetivos, quando se leva em conta a frequência e dominância destas espécies nas flores de I. carnea subs. fistulosa. De acordo com Gathmann \& Tscharntke (2002), para que ocorra a reprodução e a sobrevivência de abelhas solitárias, uma quantidade suficiente de diferentes recursos deve estar dentro da área de forrageio, ao alcance das fêmeas. Estes recursos incluem locais específicos de nidificação, materiais para a construção de ninhos, recursos alimentares para manter as atividades das abelhas adultas e pólen e néctar como componente essencial para a alimentação das larvas (Gathmann \& Tscharntke, 2002; Westrich, 1996). Um estudo realizado por Tscharntke et al. (1998) sugere abelhas solitárias como indicadores de qualidade de hábitat ou de mudança ambiental.

Quanto às espécies de Diptera que visitaram as flores de I. carnea subs. fistulosa, não foram identificadas diferenças significativas entre as áreas no que diz respeito a abundância e riqueza. Porém, com relação a composição de espécies a área preservada apresentou cinco espécies da família Syrphidae que não ocorreram na área urbana ao longo do período de estudos. $\mathrm{Na}$ área preservada foram registrados representantes da família Muscidae e Syrphidae e para a área urbana ocorreu o registro apenas de espécies de Muscidae.

Segundo Macalpine (1981), as larvas de Syrphidae são predadoras de estágios imaturos de Coleoptera e Lepidoptera, este grupo provavelmente é importante no controle de homopteros, pragas de plantas cultivadas. Além disso, de acordo com Buchs et. al (2003), os Syrphidae são muito sensíveis aos agrotóxicos e fertilizantes no solo. Os representantes de Syrphidae não têm sido encontrados em áreas agrícolas ou degradadas, em função da alta exigência de serapilheira e umidade para sua sobrevivência (Frouz, 1999), portanto, são bons bioindicadores. Assim, a ocorrência desta família de dípteros na área preservada pode estar relacionada ao fato de se tratar de uma fazenda biodinâmica, ressaltando ainda mais a importância do uso consciente e sustentável dos recursos naturais para a preservação das relações ecológicas.

\section{Herbívoros}

Dentre os herbívoros, foram poucas as espécies que ocorreram em ambas as áreas, com diferenças na abundância, riqueza e composição de espécies entre as áreas.

Dentre os coleópteros, a família Chrysomelidae foi mais numerosa, tanto na área preservada quanto na área urbana e acerca dela há muitos estudos relacionados diretamente com espécies do gênero Ipomoea (Frey, 1995; Deval \& Thien 1989; Crawley 1983; Keeler 1975). No presente estudo, essa família foi representada por sete subfamílias (Galerucinae, Cassidinae, Alticinae, Eulmopinae, Bruchinae, Cryptocephalinae e Chrysomelinae) na área preservada, porém, destas, apenas quatro (Galerucinae, Cassidinae, Eulmopinae e Bruchinae) também ocorreram na área urbana, sendo representadas por uma ou poucas espécies.

A subfamília Galerucinae apresentou apenas duas morfoespécies, entre estas Diabotrica. speciosa foi a espécie mais abundante e comum a ambas as áreas, onde, de acordo com Haji (1981) e Gassen (1989), é uma praga polífaga que afeta diversas culturas no Brasil. Dessa maneira, estudos detalhados sobre o papel destes insetos para as populações de I. carnea subs. fistulosa indicam que elas podem ser fontes potenciais de controle biológico e investigações adicionais devem ser realizadas no futuro. 
O Cassidinae Charidotella sexpunctata foi o segundo herbívoro mais abundante, porém estava presente apenas na área preservada. Danos causados por cassidíneos em espécies do gênero Ipomoea foram registrados em outros estudos, como em Fidalgo (1997) para Ipomoea carnea subs. fistulosa, Paleari (1997) e I. asarifolia, e Nora (1993) para I. batatas. Esta subfamília de Crisomelídeos é a mais especializada em plantas tóxicas (Jolivet, 1988), alimentando-se de poucos gêneros vegetais.

O dano causado aos botões florais por espécies da subfamília Alticinae também foi registrado por Santos \& Del-Claro (2001) para uma espécie de Rubiaceae no cerrado, mas não foram encontrados registros de outras ocorrências destes herbívoros em Ipomoea.

A subfamília, Eulmopinae (Chrysomelidae) contém o maior número de espécies fitófagas do mundo. A maioria de suas espécies está associada diretamente com a predação foliar, quando adultos, e, quando em fase larval, nas raízes ou mesmo nas folhas (Xing-Peng $\&$ Cheng, 2007). Entretanto, no experimento foi encontrada dentro das flores, diferindo da literatura, onde, na grande maioria dos casos, é considerada simplesmente predadora foliar. No Brasil existem poucos relatos de herbivoria por eumolpíneos, mas são conhecidas suas notórias associações com plantações de "cacau" (Theobroma cacao L.) na região sul da Bahia (Ferronato, 2001), e eles são considerados como pragas desta cultura.

A subfamília Bruchinae destaca-se por ser um dos principais grupos de insetos que predam sementes durante o desenvolvimento larval (Johnson, 1981; Janzen, 1969). Bruquíneos adultos são conhecidos por se alimentar apenas de pólen e néctar (Johnson et al., 1995) e, neste estudo, foi a subfamília com o maior número de morfoespécies para ambas as áreas. A predação de sementes por bruquíneos foi registrada para a família Convolvulaceae, por Johnson et al. (1995) e Johnson (1981).

Considerando a família Nitidulidae, esta foi representada neste estudo por apenas uma espécie comum a ambas as áreas, nas flores de Ipomoea carnea subs. fistulosa. Guerrero-Olaya \& Núñez-Avellaneda, 2017 apontam membros desta família como sendo polinizadores, porém no presente trabalho, usando como modelo ecológico a espécie I. carnea subs.fistulosa, a espécie do gênero Conetelus consumiu grande quantidade de grãos de pólen, chegando até mesmo a danificar as anteras.

Espécies da família Nitidulidae foram responsáveis por danos em flores de Amphilophium vauthieri (Bignoniaceae), em uma floresta semidecídua de Campinas (SP), prejudicando a frutificação dessas lianas (Amaral, 1992). Há ainda espécies da família Nitidulidae que consomemfrutos, sementes e pólen (Kupinick et al., 1999). No entanto, ainda não havia sido registrada a presença da família em flores de Ipomoea carnea subs. fistulosa.

Durante a estação seca na caatinga, Ipomoea carnea subs. fistulosa é uma das poucas espécies que persistem com folhas e flores, fato que faz com que as populações de I. carnea subs. fistulosa constituam grandes manchas indicadoras de recursos para os herbívoros presentes naquela vegetação. Esta pode ter sido uma das principais causas para que a abundância de herbívoros associados a esta espécie tenha sido mais alta nos meses com menor precipitação.

O padrão do aumento da abundância de herbívoros em manchas com maior concentração de recursos foi também encontrado por outros autores (Denno, 2012; Tahvanainen \& Root 1972; Wilson \& Janzen 1972; Ralph 1977; Meijden 1979; Raupp \& Denno 1979; Schmitt 1983). Isto pode ser devido ao fato de que manchas com maior quantidade de recursos (i.e. com maior número de flores) podem ser indicadoras da qualidade da planta hospedeira, e os herbívoros visitantes podem estar respondendo à esta variável. Além disso, muitos insetos herbívoros localizam a planta através de pistas olfativas (Solomon, 1981), assim, flores mais agregadas poderiam ser mais facilmente localizadas.

Segundo a hipótese de concentração de recursos (Root, 1973), os herbívoros seriam atraídos diferencialmente para áreas com maior disponibilidade de recursos. A ocorrência de plantas hospedeiras em grandes concentrações ou em alta abundância relativa deve atrair maior número de insetos herbívoros, se comparada com locais onde ocorrem hospedeiros relativamente menos agregados. Esta hipótese foi apoiada com base nos estudos do comportamento de várias espécies de insetos (Meijden, 1979; Raupp \& Denno, 1979; Ralph, 1977; Tahvanainen \& Root 1972; Wilson \& Janzen, 1972). Esse fator pode justificar a maior abundância de herbívoros na área preservada, por se tratar de um ecossistema natural, Ipomoea carnea subs. fistulosa, é um dos poucos e raros recursos disponíveis para os herbívoros nos períodos de estiagem.

\section{Predadores (inimigos naturais)}

Dentre os predadores Formicinae foi a subfamília dominante em ambas as áreas, apresentando um maior número de espécies e maior abundância na área preservada tanto em 
número de espécies e abundância, seguida de Myrmicinae, esse padrão de distribuição é característico de ambientes mais abertos (Leal 2003, 2002; Marinho et al., 2002). Quanto as áreas, para este grupo de predadores não diferiram significativamente quanto a riqueza e abundância, porém tanto a abundância quanto a riqueza foram maiores para a área preservada. Estudos recentes têm mostrado que a abundância e riqueza das associações formigas-plantas são particularmente significativas na região tropical (Garcia et al., 2013; Rodrigues, 2008; Del-Claro et al., 1996; Oliveira \& Pie, 1998).

A atividade das formigas sobre a vegetação pode gerar uma enorme variedade de interações formigas-plantas-herbívoros (Beattie, 1985; Davidson \& Mckey, 1993; Bronstein, 1998; DelClaro, 2004). As análises de abundância de formigas e herbívoros na área preservada indicam que esta espécie parece se enquadrar nessa discussão, haja visto que, nos meses com menor precipitação, ocorreram as maiores abundâncias de herbívoros e, consequentemente, de formigas associadas a nectários extraflorais. A abundância de mutualismos entre formigas e plantas é particularmente notável em hábitats tropicais (Bronstein, 1998). Porém, outros artrópodes podem competir com as formigas pelos NEFs, como vespas predadoras, o mesmo foi observado por O'Dowd (1979) e Heil et al. (2003).

Geralmente, os estudos têm resultado em maior riqueza de espécies de formigas, associada a maior riqueza de espécies de plantas e, também, ao tempo decorrido do processo de recomposição das áreas que sofreram algum tipo de distúrbio. Isso corrobora a hipótese de que os ambientes mais complexos podem oferecer melhores condições para a manutenção e sobrevivência de maior número de espécies da mirmecofauna (Andersen, 1986; Carvalho \& Vasconcelos, 2002). Fatores como a heterogeneidade da serapilheira (Brühl et al., 1998), as condições climáticas (Levings, 1983), a complexidade estrutural e a heterogeneidade da vegetação podem modificar as condições ambientais e, consequentemente, a diversidade da fauna de formigas (Oliveira et al., 2011).

A abundância e riqueza de aranhas foram maiores na área preservada. E especificamente na área urbana a riqueza de aranhas foi muito baixa, o que pode ser justificado pela degradação desta área. De acordo com Uetz (1991) devido à grande riqueza em espécies, 38.663 espécies (Platnick, 2004) e à sensibilidade a diversos fatores ambientais, as aranhas formam um grupo taxonômico indicado para avaliar o estado de conservação de fragmentos florestais, visto que a estrutura do habitat pode influenciar bastante a composição e a riqueza das comunidades de aranhas de florestas tropicais (Uetz, 1991). Höfer \& Brescovit (2001) sugerem o uso das mesmas como bioindicadores para diagnóstico de uma determinada área.

A abundância de aranhas e polinizadores responderam positivamente a precipitação pluviométrica na área preservada, onde ambos os grupos tróficos apresentaram maiores abundâncias no período chuvoso, o que pode gerar redução do fitness das abelhas como potenciais polinizadores, e por isso este aspecto deve ser melhor investigado futuramente.

Dentre os coleópteros predadores, todos os indivíduos coletados pertencem a família Coccinellidae, de modo que das sete espécies registras para a área preservada, apenas quatro ocorreram na área urbana, com baixa abundância e frequência ao longo do período de amostragem. Considerando a área preservada a abundância de Coccinellidae foi maior e com maior frequência, tendo a espécie Coleomegilla maculata como sendo a mais abundante. Os Coleoptera da família Coccinellidae são popularmente conhecidos como joaninhas, e a maioria de suas espécies é predadora de outros insetos (Silva et al., 2011). Segundo estes mesmos autores, ocorrem frequentemente sobre vegetais onde suas presas geralmente se encontram, ou onde se alimentam, pois há espécies fitófagas. Várias espécies são consideradas benéficas, pois atacam afídios e cochonilhas. Iperti (1999) salienta que as condições microclimáticas e os fatores alimentares são importantes na determinação do hábitat de besouros da família Coccinellidae, pois cada espécie apresenta preferências quanto ao tipo de estrato vegetal e diferente sazonalidade. Portanto, o declínio das comunidades desta família é influenciado pela urbanização intensa e pelo uso de agrotóxicos. Algumas espécies são muito vulneráveis às mudanças ambientais, devido ao aumento da poluição química e física, aumento do cultivo de cereais (os quais criam problemas na cadeia trófica) e ao impacto de flutuações climáticas.

Os coccinelídeos apresentam grande atividade de busca, ocupando todos os ambientes de suas presas, o que os caracteriza como predadores de ácaros fitófagos, cochonilhas, psilídeos, pulgões, moscas-branca, ovos e larvas neonatas de Coleoptera e Lepidoptera (Silva et al., 2009; Ozgohçe et al., 2006; Stathas, 2000; Hoballah et al., 2004). Além disto, podem ser criadas com relativa facilidade em laboratório, aumentando as vantagens das espécies para uso em programas de controle biológico. Tais insetos podem desempenhar um papel muito importante na supressão das principais pragas. 
A espécie Coleomegilla maculata, muito abundante na área preservada, tem sido estudada para avaliar sua eficiência no controle biológico de vários insetos adultos e em fase larval (Cruz, et al. 2011; Silva et al., 2010; Munyaeza \& Obrycki, 1998).

Considerando a área preservada, ocorreu a presença de um quarto nível trófico, que são os parasitóides, no presente estudo foi representado por uma vespa do gênero Conura (Família Chalcididae) e outra do gênero Epipompilus (Família Pompilidae). Estes organismos podem realizar o controle de populações de herbívoros, além de poderem parasitar algumas espécies de predadores, desempenhando importante papel na dinâmica das interações planta-animal. Marchior (2001) fez o primeiro registro de Conura sp. parasitando ovos de um Diptera, predador da família Syrphidae. Porém, existe um número de estudos ainda maior, quando se trata de controle biológico de insetos herbívoros (Silva et al., 2012; Boucek, 1988).

Os Pompilidae são todos exclusivamente ectoparasitoides (põem seus ovos externamente sobre seus hospedeiros) de aranhas (Wasbauer, 1995), e não podem ser considerados como insetos predadores, pois não aprovisionam ovos (presas), e são exclusivamente insetos parasitoides, pois utilizam apenas um indivíduo, no caso um hospedeiro, para alimentar uma única ou várias larvas (Askew, 1971). Porém, a biologia e a ecologia de Epipompilus são desconhecidas, assim, apesar da importância ecológica e econômica de insetos parasitoides, são escassos os levantamentos faunísticos amplos que tratam da diversidade (Perioto et al., 2015), tornando necessário esse tipo de estudo para que sejam identificadas estratégias de conservação das espécies.

De maneira geral, considerando a área preservada, a abundância de aranhas e polinizadores respondeu positivamente à precipitação pluviométrica, onde ambos os grupos tróficos apresentaram maior abundância no período chuvoso, o que pode gerar redução do fitness das abelhas como potenciais polinizadores, e, por isso, este aspecto deve ser melhor investigado futuramente. Considerando a área urbana, a abundância de predadores respondeu positivamente à abundância de herbívoros, com maior pico no período seco, padrão similar na variação da abundância de predadores foi observada por Rzanny et al. (2013) e Folkard \& Smith (1995).

Assim o padrão de abundância aqui apresentado para a área preservada deve estar associado ao fato de se tratar de uma fazenda biodinâmica, além da presença de uma área de reserva. Enquanto que na área urbana houve uma significativa redução de riqueza e abundância de artrópodes associados a Ipomoea carnea subs. fistulosa, assim em ambientes fragmentados que sofrem intensa ação antrópica, pode ocorrer uma redução na densidade e riqueza em espécie, assim como uma alteração na estrutura e dinâmica das comunidades de plantas e as interações a cerca delas, o que justifica o padrão de abundância e riqueza de espécies registrado para a área urbana.

\section{Conclusão}

Para um mesmo sistema multitrófico (Ipomoea carnea subs. fistulosa), a área preservada apresentou uma maior complexidade, abundância e riqueza de espécies para cada nível trófico, havendo, ainda, um nível trófico a mais do que na área urbana.

Diante dos resultados aqui mostrados, a alta velocidade de destruição de florestas tropicais, aliada à extinção de espécies, exige o desenvolvimento de estratégias de conservação e uso sustentável dos fragmentos remanescentes, bem como de recuperação de áreas degradadas.

\section{Agradecimentos}

Ao Programa de Pós-Graduação em Ecologia da UFRPE e à Coordenação de Aperfeiçoamento de Pessoal de Nível Superior (CAPES) pelo apoio financeiro. À Fazenda Tamanduá, pelo apoio logístico. Ao Mrs. Pedro Santos Neto e ao Dr. José Domingos Ribeiro Neto pela identificação das espécies de abelhas e formigas, respectivamente, bem como ao Dr. Arno Antônio Lise, pela determinação das espécies de aranhas. Adicionar agradecimento pela Bolsa de Produtividade de Almeida-Cortez.

\section{Referências}

ALBUQUERQUE, U. P.; ARAÚJO, E. L.; ARAÚJO, E. L.; ASFORA-ELDEIR, A. C.; LIMA, A. L. A. ; SOUTO, A.; BEZERRA, B.M.; FERRAZ, E. M. N.; FREIRE, E. M. X.; SAMPAIO, E. V. S. B.; LAS-CASAS, F. M. G.; MOURA, G. J. B.; PEREIRA, G. A.; MELO, J. G.; RAMOS, M. A.; RODAL, M. J. N.; SCHIEL, N.; LYRA-NEVES, R. M.; ALVES, R. R. N.; AZEVEDO-JUNIOR, S. M.; TELINO JUNIOR, W. R.; SEVERI, W. 2012. Caatinga Revisited: Ecology and Conservation of an Important Seasonal Dry Forest. The Scientific World Journal, v. 2012, p. 1-18.

AMARAL, M. E. C. 1992. Ecologia floral de dez espécies da tribo Bignonieae (Bignoniaceae), em uma floresta semidecídua no município de 
Campinas, SP. Tese de Doutorado, Universidade Estadual de Campinas, Campinas, SP, Brasil. 189p.

ANDENA, S. R.; BEGO, L. R.; MECHI, M. R. 2009. A comunidade de abelhas (Hymenoptera, Apoidea) de uma área de cerrado (Corumbataí, SP) e suas visitas às flores. Revista Brasileira de Zoociências, v. 7, n. 1, p. 55-91.

ANDERSEN, A. N. 1986. Patterns of ant community organization in mesic southeastern Australia. Austral Ecology, v. 11, n. 1, p. 87-97.

ASKEW, R. R. et al. 1971. Parasitic insects. 316p.

BEATTIE, A. J. 1985. The evolutionary ecology of ant-plant mutualisms. Cambridge University Press.

BOUČEK, Z. et al. 1988. Australasian Chalcidoidea (Hymenoptera). A biosystematic revision of genera of fourteen families, with a reclassification of species. Cab International. 832p.

BRONSTEIN, J. L. 1998. The contribution of antplant protection studies to our understanding of mutualism. Biotropica, v. 30, n. 2, p. 150-161.

BRUHL, C. A.; GUNSALAM, G.; LINSENMAIR, K. E. 1998. Stratification of ants (Hymenoptera, Formicidae) in a primary rain forest in Sabah, Borneo. Journal of Tropical Ecology, v. 14, n. 3, p. 285-297.

BÜCHS, W.; HARENBERG, A.; ZIMMERMANN, J.; WEIB, B. 2003. Biodiversity, the ultimate agri-environmental indicator?: potential and limits for the application of faunistic elements as gradual indicators in agroecosystems. Agriculture, Ecosystems \& Environment, v. 98, n. 1-3, p. 99-123.

CABRAL, G. A. L.; SAMPAIO, E. V. S. B.; ALMEIDA-CORTEZ, J. S. 2013. Spatial Structure and Aboveground Biomass in Different Caatinga Succession Stages, in Santa Terezinha, Paraiba. Revista Brasileira de Geografia Física, v. 6, p. 566574.

CARVALHO, K. S.; VASCONCELOS, H. L. 2002. Comunidade de formigas que nidificam em pequenos galhos da serrapilheira em floresta da Amazônia Central, Brasil. Revista Brasileira de Entomologia, v. 46, n. 2, p. 115-121.

CRAWLEY, M. J. 1983. Herbivory. The dynamics of animal-plant interactions. Blackwell Scientific Publications.
CROMARTIE JR., W. J. 1975. The effect of stand size and vegetational background on the colonization of cruciferous plants by herbivorous insects. Journal of Applied Ecology, v. 12, p. 517533.

CRUZ, I.; REDOAN, A. C.; SILVA, R. B.; FIGUEIREDO, M. L. C.; PENTEADO-DIAS, A. M. 2011. New record of Tetrastichus howardi (Olliff) as a parasitoid of Diatraea saccharalis (Fabr.) on maize. Scientia Agricola, v. 68, p. 252 254.

DAVIDSON, D. W.; MCKEY, D.1993. Ant-plant symbioses: stalking the Chuyachaqui. Trends in Ecology \& Evolution, v. 8, n. 9, p. 326-332.

DEL-CLARO, K.; BERTO, V.; RÉU, W. 1996. Effect of herbivore deterrence by ants on the fruit set of an extrafloral nectary plant, Qualea multiflora (Vochysiaceae). Journal of Tropical Ecology, v. 12, n. 6, p. 887-892.

DENNO, R. (Ed.). 2012. Variable plants and herbivores in natural and managed systems. Elsevier.

DEVALL, M. S.; THIEN, L. B. 1989. Factors influencing the reproductive success of Ipomoea pes-caprae (Convolvulaceae) around the Gulf of Mexico. American Journal of Botany, v. 76, n. 12, p. 1821-1831.

EDWARDS, P. J.; WRATTEN, S. D. 1981. Ecologia das interações entre insetos e plantas. São Paulo, EDUSP. v. 27, 71p.

FERRONATO, M. L. 2001. Aprimoramento de atributos comercialmente desejáveis em Aster sp. cultivar White Master através do uso de reguladores do crescimento vegetal. Scientia Agraria, v. 2, n. 1, p. 130-130, 2001.

FIDALGO, A. O. 1997. Ecologia floral de duas espécies invasoras de Ipomoea (Convolvulaceae). Tese de Mestrado. Unicamp, Campinas, SP, Brasil. $84 p$.

FOLKARD, N. F. G.; SMITH, J. N. M. 1995. Evidence for bottom up effects in the boreal forest: do passerine birds respond to large-scale experimental fertilization? Can. J. Zool., v. 73, p. 2231-2237.

FREY, R. 1995. Ipomoea carnea ssp. fistulosa (Martius ex Choisy) Austin: taxonomy, biology 
and ecology reviewed and inquired. Tropical Ecology, v. 36, n. 1, p. 21-48.

FRIEBE, B. 1983. Zur Biologie eines Buchenwaldbodens: 3. Die Käferfauna. Carolinea, Karlsruhe, v. 41, p. 45-80.

FROUZ, J. 1999. Use of soil dwelling Diptera (Insecta, Diptera) as bioindicators: a review of ecological requirements and response to disturbance. Agriculture, Ecosystems \& Environment, v. 74, p. 167-186.

GASSEN, D. N. 1989. Insetos subterrâneos prejudiciais às culturas no sul do Brasil. Passo Fundo, EMBRAPA-CNPT, 49p.

GATHMANN, A.; TSCHARNTKE, T. 2002. Foraging ranges of solitary bees. Journal of Animal Ecology, v. 71, n. 5, p. 757-764.

GUERRERO-OLAYA, N. Y.; NÚÑEZAVELLANEDA, L. A. 2017. Ecología de la polinización de Syagrus smithii (Arecaceae), una palma cantarofila de la Amazonia Colombiana. Revista Peruana de Biología, v. 24, n. 1, p. 43-54.

GULLAN, P. J.; GULLAN, P. J.; CRANSTON, O. S. 2007. Os insetos: um resumo de entomologia. Editora Roca Ltda, São Paulo, 440p.

GULLAN, P. J.; CRANSTON, O. S. 2008. Os insetos: um resumo de entomologia. 3 ed. São Paulo: Roca, 440p.

HAJI, N. F. P. 1981. Biologia, dano e controle do adulto de Diabrotica speciosa (Germar, 1824) (Coleoptera: Chrysomelidae) na cultura da batatinha (Solanum tuberosum L.). Tese de Doutorado. Escola Superior de Agricultura Luiz de Queiroz, Piracicaba, SP, Brasil. 53p.

HAYMÉE, N. A.; SANTOS, J. S.; SANTOS, B. A. S. 2018. Herbivoria e sua relação com as condições microclimáticas e de uso do solo em uma floresta tropical úmida. Gaia Scientia, v. 12, n. 1, p. 42-55.

HEIL, M.; HILPERT, A.; KRÜGER, R.; LINSENMAIR, K.E. 2003. Competition among visitors to extrafloral nectaries as a source of ecological costs of an indirect defence. Journal of Tropical Ecology, v. 20, p. 201-208.

HOBALLAH, E. M.; KÖLLNER, G. T.; DEGENHARDT, J.; TURLINGS, C. J. T. 2004. Costs of induced volatile production in maize. Oikos, v. 105, n. 1, p. 168-180.
HÖFER, H.; BRESCOVIT, A. D. 2001. Species and guild structure of a Neotropical spider assemblage (Araneae) from Reserva Ducke, Amazonas, Brazil. Andrias, v. 15, p. 99-119.

HUTCHESON, J. 1990. Characterization of terrestrial insect communities using quantified, Malaise-trapped Coleoptera. Ecological entomology, v. 15, n. 2, p. 143-151.

ICO, G.; THOMPSON, S. E.; MANZONI, S.; MOLINI, A.; ALBERTSON, J. D.; ALMEIDACORTEZ, J. S.; FAY, P. A.; FENG, X.; GUSWA, A. J.; LIU, H.; WILSON, T. G.; PORPORATO, A. 2014. Climatic, ecophysiological and phenological controls on plant ecohydrological strategies in seasonally dry ecosystems. Ecohydrology, v. 8, n. 4, p.660-681.

IPERTI, G. 1999. Biodiversity of predaceous Coccinellidae in relation to bioindication and economic importance. Agriculture Ecosystems \& Environment, v. 74, p. 323-342.

JANZEN, D. H. 1969. Seed-eaters versus seed size, number, toxicity and dispersal. Evolution, v. 23, p. 1-27.

JOHNSON, C. D. 1981. Seed beetle host specificity and the systematics of the Leguminosae. In: POLHILL, R. M.; RAVEN, P. H. (eds). Advances in Legume Systematics, Part 2. Royal Botanic Gardens, Kew, England, pp. 995-1027.

JOHNSON, C. D.; ZONA, S.; NILSSON, J. A. 1995. Bruchid beetles and palm seeds: recorded relationships. Principes, v. 39, p. 25-35.

JOLIVET, P. 1988. Food habits and food selection of Chrysomelidae: bionomic and evolutionary perspectives. Pp. 1-24. In: JOLIVET, P.; PETITPIERRE, E.; HSIAO, T. H. (eds) The Biology of the Chrysomelidae. NL-Dordrecht: Kluwer Academic Publishers.

KEELER, K. H. 1975. Ipomoea carnea Jacq. (Convolvulaceae) in Costa Rica. Brenesia, v. 5, p.1-5.

KIILL, L. H. P.; MARTINS, C. T. D. V. D.; SILVA, T. A.; SANTOS, J. T. L. 2018. Ecologia da polinização de Ipomoea longistaminea O'Donell (Convolvulaceae) na região semiárida da Bahia. Ambiência, v. 13, n. 3, p. 684-701.

KIILL, L. H. P.; RANGA, N. T. 2003. Ecologia da Polinização de Ipomoea asarifolia (Ders.) Roem e 
Schult. (Convolvulaceae) na região semi-árida de Pernambuco. Acta Bot. Bras., v. 17, n. 3, p. 355362.

LEAL, I. R. 2002. Diversidade de formigas no estado do Pernambuco. Pp. 483-492. In: SILVA, J. M.; TABARELLI, M. (orgs.) Atlas da Biodiversidade de Pernambuco, Editora Massangana e SECTMA, Recife.

LEAL, I. R. 2003. Diversidade de formigas em diferentes unidades da paisagem da Caatinga, pp. 435-460. In: LEAL, I. R.; TABARELLI, M.; SILVA, J. M. (eds.), Ecologia e conservação da Caatinga. Editora da Universidade Federal de Pernambuco, Recife, 802p.

LEVINGS, S. C. 1983. Seasonal, annual, and among-site variation in the ground ant community of a deciduous tropical forest: some causes of patchy species distributions. Ecological Monographs, v. 53, n. 4, p. 435-455.

LOPES, L. A.; BLOCHTEIN, B.; OTT, A. P. 2007. Diversidade de insetos antófilos em áreas com reflorestamento de eucalipto, município de Triunfo, Rio Grande do Sul, Brasil. Iheringia, Série Zoológica, v. 97, n. 2, p. 181-193.

LOPES, L. A.; BLOCHTEIN, B.; OTT, A. P. 2007. Diversidade de insetos antófilos em áreas com reflorestamento de eucalipto, município de Triunfo, Rio Grande do Sul, Brasil. Iheringia, Série Zoológica, v. 97, n. 2, p. 181-193.

MACALPINE, J. E. 1981. Manual of Neartic Diptera. Vol. II. Quebec: Research Branche Agriculture Canada, 1332p.

MAGON, G.; KAWAKITA, J. K.; MIOTTO, S. S. T.; SOUZA, C. M. 2013. O gênero Crotalaria L. (Leguminosae, Faboideae, Crotalarieae) na Planície de Inundação do Alto Rio Paraná, Brasil. Revista Brasileira de Biociências, v. 11, n. 2, p. 209-226.

MAIMONI-RODELLA, R. C. S.; YANAGIZAWA, Y. 2007. Floral biology and breeding system of three Ipomoea weeds. Planta Daninha, v. 25, p. 35-42.

MAIMONI-RODELLA, R. C. S.; YANAGIZAWA, Y. 2007. Floral biology and breeding system of three Ipomoea weeds. Planta Daninha, v. 25, p. 35-42.
MARINHO, C. G. S.; ZANETTI, R.; DELABIE, J. H. C.; SCHLINDWEIN, M. N.; RAMOS, L. S. 2002. Diversidade de formigas (Hymenoptera: Formicidae) da serapilheira em eucaliptais (Myrtaceae) e área de Cerrado de Minas Gerais. Neotropical Entomology, v. 3, p. 187-195.

MEIJDEN E, VAN D. 1979. Herbivore exploitation of a fugitive plant species: local survival and extinction of the cinnabar moth and ragworth in a heterogenous environment. Oecologia, v. 42, p. 307-323.

MUNYANEZA, J.; OBRYCKI, J. J. 1998. Development of three populations of Coleomegilla maculata (Coleoptera: Coccinellidae) feeding on eggs of Colorado potato beetle (Coleoptera: Chrysomelidae). Environmental Entomology, v. 27, p. 117-122.

O'DOWD, D. J. 1979. Foliar nectar production and ant activity on a neotropical tree. Ochroma pyramidale. Oecologia, v. 4, n. 3, p. 233-248.

OLIVEIRA M. T.; DINIZ, A. E.; MUNHAE, B. C.; BUENO, C. O.; MORINI, C. M. S. 2011. Composição da fauna de formigas (Hymenoptera: Formicidae) de serapilheira em florestas semidecídua e de Eucalyptus spp., na região sudeste do Brasil. Biota Neotropica, v. 11, n. 2, p. 237-246.

OLIVEIRA, M. D.; BARBOSA, P. R.; SILVATORRES, C. S.; SILVA, R. R.; BARROS, E. M.; TORRES, J. B. 2014. Reproductive performance of striped mealybug Ferrisia virgata Cockerell (Hemiptera: Pseudococcidae) on water-stressed cotton plants subjected to nitrogen fertilization. Arthropod-Plant Interactions, v. 8, n. 5, p. 461-468.

OLIVEIRA, O. S.; FREITAS, A. V. L. 2004. Antplant-herbivore interactions in the neotropical cerrado savana. Naturwissenachaften, v. 91, p. 557-570.

OZGOK, C. E.; ATLIHAN, M. S. R.; KARA C. A. I. 2006. The life table of Cryptolaemus montrouzieri Mulsant (Coleoptera: Coccinellidae) after different storage periods. Journal of Food, Agriculture \& Environment, v. 4, p. 282-287.

PACHECO FILHO, A. J. S.; VEROLA, C. F.; VERDE, L. W. L.; FREITAS, B. M. 2015. Beeflower association in the Neotropics: implications to bee conservation and plant pollination. Apidologie, v. 46, n. 4, p. 530-541. 
PALEARI, L. M. 1997. Partilha de Recursos entre Botanochara sedecimpustulata (Fabricius, 1781) e Zatrephina lineata (Fabricius, 1787) (Coleoptera, Chrysomelidae, Cassidinae), em Ipomoea asarifolia (Convolvulaceae), na Ilha de Marajó, Pará, Brasil. Tese de doutorado. Universidade Estadual de Campinas, Campinas, SP, Brasil. 109p.

PAZ, J. R. L.; SILVA, W. P.; PIGOZZO, C. M. 2016. Vespas aculeata e abelhas visitantes de nectários extraflorais em Ipomoea carnea subsp. fistulosa no semiárido baiano, Nordeste do Brasil. Boletim do Museu de Biologia Mello Leitão, v. 38, n. 2, p. 73-180.

PERIOTO, N. W.; LARA, R. I. R.; VACARI, A. M.; FAVORETO, L.; MIRANDA, N. F.; CHAGAS FILHO, N. R.; PESSOA, R. 2015. Diversidade de himenópteros parasitóides (Hymenoptera) na Estação Ecológica de Jataí, Luiz Antônio, SP, Brasil. Brazilian Journal of Agriculture-Revista de Agricultura, v. 83, n. 2, p. 125-135.

PERIOTO, N. W.; LARA, R. I. R.; VACARI, A. M.; FAVORETO, L.; MIRANDA, N. F.; CHAGAS FILHO, N. R.; PESSOA, R. 2015. Diversidade de himenópteros parasitóides (Hymenoptera) na Estação Ecológica de Jataí, Luiz Antônio, SP, Brasil. Brazilian Journal of Agriculture-Revista de Agricultura, v. 83, n. 2, p. 125-135.

PRICE, P. W.; BOUTON, C. E.; GROSS, P.; MCPHERON, B. A.; THOMPSON, J. N.; WEIS, A. E. 1980. Interactions among three trophic levels: influence of plants on interactions between insects, herbivores and natural enemies. Annual Review of Ecology and Systematics, v. 11, p. 41-65.

RALPH, C. P. 1977. Effect of host plant density on population of a specialized seed sucking bug, Oncopeltus fasciatus. Ecology, v. 58, p. 799-809.

RAUPP, M. J.; DENNO, R. E. 1 979. The influence of patch size on a guild of sap-feeding insects that inhabit the salt marsh grass Spartina patens. Environmental Entomology, v. 8, p. 412-417.

RODRIGUES, C. A.; ARAÚJO, M. S.; CABRAL, P. I. D.; LIMA, R.; BACCI, L.; OLIVEIRA, M. A. 2008. Comunidade de formigas arborícolas associadas ao pequizeiro (Caryocar brasiliense) em fragmento de Cerrado Goiano. Pesquisa Florestal Brasileira, n. 57, p. 39.
ROOT, R. B. 1973. Organization of a plantarthropod association in simple and diverse habitats: the fauna of collards (Brassica oleracea). Ecological monographs, v. 43, n. 1, p. 95-124.

RZANNY, M.; KUU, A.; VOIGT, W. 2013. Bottom-up and top-down forces structuring consumer communities in an experimental grassland. Oikos, v. 122, n. 7, p. 967-976.

SANTOS, J. C.; FERNANDES, G. W.; LEAL, I. R.; ALMEIDA-CORTEZ, J. S.; TABARELLI, M. 2011. Caatinga: The Scientific Negligence Experienced by a Dry Tropical Forest. Tropical Conservation Science, v. 4, p. 276-286.

SANTOS, J.C.; DEL-CLARO, K. 2001. Interação entre formigas, herbívoros e nectários extraflorais em Tocoyena formosa (Cham. \& Schlechtd.) K. Schum. (Rubiaceae) na vegetação do cerrado. Revista Brasileira de Zoociências, v. 3, n. 1, p. 7792.

SCHLISING, R. A. 1970. Sequence and timing of bee foraging in flowers of Ipomoea and Aniseia (Convolvulaceae). Ecology, v. 51, p. 1961-1067.

SCHRNITT, J. 1983. Flowering plant density and pollinator visitation in Sellecio. Oecologia, v. 60, p. 97-102.

SILVA, A. G.; SOUZA, B. H. S.; RODRIGUES, N. E. L.; BOTTEGA, D. B.; JUNIOR, A. L. B. 2012. Interação tritrófica: aspectos gerais e suas implicações no manejo integrado de pragas. Nucleus, v. 9, n. 1, 14p.

SILVA, B. L. R.; ALMEIDA-CORTEZ, J. S.; TAVARES, F. M. 2012. Composição Florística do Componente Herbáceo de uma Área de Caatinga Fazenda Tamanduá, Paraíba, Brasil. Revista de Geografia, v. 29, p. 54-64.

SILVA, P. G.; SILVA, F. C. G. 2011. Besouros (Insecta: Coleoptera) utilizados como bioindicadores. Revista Congrega URCAMP, v. 5, n. 1, p. 1-16.

SILVA, R. B.; CRUZ, I.; FIGUEIREDO, M. L. C.; TAVARES, W. S. 2010. Development of Coleomegilla maculata De Geer (Coleoptera: Coccinellidae) with prey and artificial diet. Revista Brasileira de Milho e Sorgo, v. 9, p. 13-26.

SILVA, R. B.; ZANUNCIO, J. C.; SERRÃO, J. E.; LIMA, E. R.; FIGUEIREDO, M. L. C.; CRUZ, I. 2009. Suitability of different artificial diets for 
development and survival of stages of predaceous ladybird beetle Eriopis connexa (Coleoptera: Coccinellidae). Phytoparasitica, v. 37, p. 115-123.

SILVEIRA NETO, S. 1976. Manual de ecologia dos insetos. São Paulo, Ceres, 419p.

SIMÃO-BIANCHINI, R.; FERREIRA, P. P. A. Ipomoea. Lista de Espécies da Flora do Brasil. Jardim Botânico do Rio de Janeiro. Disponível em: http://floradobrasil.jbrj.gov.br/jabot/floradobrasil/ FB126374. Acesso em: 05-01- 2015.

SOLOMON, B. P. 1981. Response of a hostspecific herbivore to resource density, relative abundance and phenology. Ecology, v. 62, p. 12051214.

STATHAS, G. J. 2000. Rhyzobius lophanthae prey consumption and fecundity. Phytoparasitica, v. 28, p. 1-9.

TAHVANAINEN, J. O.; ROOT, R. B. 1972. The influence of vegetational diversity on the population ecology of a specialized herbivore, Phyllotreta cruciferae (Coleoptera: Chrysomelidae). Oecologia, v. 10, n. 4, p. 321-346.

TAHVANAINEN, J. O.; ROOT, R. B. 1972. The influence of vegetational diversity on the population ecology of a specialized herbivore, Phyllotreta cruciferae (Coleoptera: Chrysomelidae). Oecologia, v. 10, n. 4, p. 321-346.

THOMPSON, J. N. 1999. The Evolution of Species Interactions. Science, v. 284, p. 21132118.

TSCHARNTKE, T.; GATHMANN, A.; STEFFAN-DEWENTER, I. 1998. Bioindication using trap-nesting bees and wasps and their natural enemies: community structure and interactions. Journal of applied ecology, v. 35, n. 5, p. 708-719.

UETZ, G. W. 1991. Habitat structure and spider foraging. In: BELL, S. S.; MCCOY, E. D.; MUSHINSKY, H. R. Habitat structure: The Physical arrangement of objects in space. London.

WASBAUER, M. S. 1995. Pompilidae. In: HANSON, P. E.; GAULD, I. D. (eds.) The Hymenoptera of Costa Rica. Oxford: Oxford University Press, pp. 522-539.

WESTRICH, P. 1996. Habitat requirements of central European bees and the problems of partial habitats. Linnean Society Symposium Series. Academic Press Limited, pp. 1-16.

WHITE, T. C. R. 1984. The abundance of invertebrate herbivores in relation to the availability of nitrogen in stressed food plants. Oecologia, v. 63, n. 1, p. 90-105.

WHITE, T. C. R. 1984. The abundance of invertebrate herbivores in relation to the availability of nitrogen in stressed food plants. Oecologia, v. 63, n. 1, p. 90-105.

WILSON, D. E.; JANZEN, D. H. 1972. Predation on Scheelea palm seeds by bruchid beetles: seed density and distance from the parent palm. Ecology, v. 53, n. 5, p. 954-959.

XING-PENG， L. I.; CHENG， D. L. I. 2007. Checklist of Eumolpinae (Coleoptera, Chrysomelidae) from Maoershan region including one new record species from China. Journal of Forestry Research, v. 18, n. 1, p. 65-68. 